\title{
La meditación de la pasión de san Juan de Ávila en el contexto del siglo XVI español
}

\author{
Jesús Pulido Arriero*
}

Fecha de recepción: junio 2021

Fecha de aceptación: octubre 2021

\section{Sumario:}

San Juan de Ávila ${ }^{1}$ desarrolló y practicó un detallado método de oración mental para la meditación diaria de la pasión, distribuyendo sus escenas en los días de la semana ${ }^{2}$. Este método no fue un invento suyo, sino que se encontraba en formación en su época y su rastro se puede seguir en propuestas similares de otros autores del siglo XVI.

El presente trabajo pretende poner de relieve el humus común a estas propuestas y comparar los diferentes desarrollos y sensibilidades entre ellas intentando identificar un género común de meditación. Para ello vamos a exponer en primer lugar los antecedentes y presupuestos de la oración mental aplicada a la pasión en la devoción de la Edad Media y en la devotio moderna. Seguida-

\section{The Meditation on the Passion of Saint John of Avila in the background of the 16th Century in Spain}

\begin{abstract}
:
The aim of the present article is to illustrate the common background in the meditation on the passion of Saint John of Avila and other Spanish authors in the 16th Century, stablishing the differences between them and trying to identify a common literary genre of meditation. First of all, we talk about the precedents of the mental prayer applied to the passion in the devotion of the Middle Ages and in the devotio moderna. Then, we present in detail both the perspective and the proposal of San Juan de Ávila. Finally, we analyze the divergences and convergences with the closest authors to him in the 16th Century who developed and practiced this same method of meditation. We conclude with some indication about the literary genre.
\end{abstract}

* Doctor en Teología (Teresianum, Pontificia Facoltà Teologica, Roma). Investigador independiente. https://orcid.org/0000-0002-0421-4589,jpulidoarriero@gmail.com.

${ }^{1}$ La biografía más reciente y completa es la de M. Jesús Fernandez Cordero, Juan de Ávila (1499?1569). Tiempo, vida y espiritualidad (Madrid 2017). La biografía clásica de referencia es L. Sala-Balust - F. Martín Hernández: Estudio biográfico, en Obras completas I (Madrid 2000) 5-373.

${ }^{2}$ Cf. J. Pulido Arriero, La meditación de la Pasión en San Juan de Ávila. Aportación a la Teología Espiritual (Tesis Doctoral, Facoltà di Teologia Teresianum, Roma 2015); Id., «Centralidad de la Pasión de Cristo en San Juan de Ávila. La Meditación devotísima de la pasión para cada día de la semana», en J. Arana Doncel-A. Llamas Vela (eds.), San Juan de Ávila, Doctor de la Iglesia. Actas del Congreso Internacional (Córdoba 2013), 569-590; Id., «"Magister, remittuntur tibi peccata tua". Contemplación del amor de Dios en San Juan de Ávila», Studia cordubensia 11 (2018) 81-109. 


\section{Jesús Pulido Arriero}

mente estudiaremos con cierto detalle tanto la intención como la propuesta de meditación propia de San Juan de Ávila. En tercer lugar, analizaremos las diferencias y convergencias del Maestro Ávila con los autores más cercanos a él en el siglo XVI que desarrollaron y practicaron este mismo método de meditación. Concluiremos con alguna indicación sobre el género literario.

\section{Palabras clave:}

Devotio moderna, Paso, Lectio, Recogimiento, Oración metódica.

\section{Keywords:}

Devotio moderna, Paso, Lectio, Recollection, Methodical prayer.

\section{La meditación de la pasión en el paso de la Edad Media a la Edad Moderna}

En los ambientes monásticos de la baja Edad Media se desarrolló la meditación de la pasión ${ }^{3}$ como medio para vencer las pasiones e iniciarse en el camino de la oración siguiendo el ritmo del claustro, el «ordo monasticus» ${ }^{4}$. En la obra «De meditatione passionis Christi per septem diei horas libellus» (1150), atribuida a San Beda el Venerable -seguramente obra de un monje cisterciense-, los misterios de la vida de Cristo y especialmente la pasión se distribuye en las horas canónicas. Su meditación se desarrolla a lo largo de la secuencia del «Opus Dei», como un elemento vivificador: en Completas se medita desde la última cena hasta el prendimiento en el Monte de los Olivos; en Maitines, el proceso religioso ante Anás y Caifás; en Prima, Jesús ante Pilato; en Tertia, Jesús ante Herodes, la flagelación y la condena a muerte; en Sexta, el camino de la cruz y las seis primeras palabras; en Nona, la séptima palabra y la muerte en cruz; en Vísperas, el descendimiento y la sepultura ${ }^{5}$.

\footnotetext{
${ }^{3}$ Sobre las muchas devociones que se desarrollaron en esta época en torno a la pasión como el viacrucis, las llagas de Jesús, las caídas, los desplazamientos de la pasión, la vía dolorosa, cf. A. Barbero, "Complessi devozionali europei dal Quattrocento al Settecento», en Saggio storico sulla devozione alla Via crucis (Ponzano, 2004), 43-61. Cf. también U. Köpf, «Passionsfrömmigkeit», en Theologische Realenzyklopadie XXVII (Berlín, 1997), 726; Fr. Vanderbroucke, «La dévotion au Crucifié à la fin du Moyen Age», La Maison-Dieu 75 (1963): 34-149.

${ }^{4}$ Cf. A. Grillmeier, «Los misterios de la vida de Jesús», en J. Feiner-M. Loehrer, Mysterium Salutis III (Madrid, ${ }^{2} 1980$ ), 571, estudia los misterios de la vida de Jesús en la espiritualidad latina y señala el giro que se produjo ya en la tradición benedictina, con los cistercienses Guillermo de Saint Thierry y Alredo de Rievaulx, que pasaron de una «teología de los misterios» a una «teología de la vida mística».

${ }^{5}$ PL 94, 561D. Encontramos ejemplos de este ejercicio también en Matilde de Magdeburgo $(\dagger$ 1280), en Matilde de Hackeborn († 1299), en la Vita Jesu Christi de Ludolfo de Sajonia. La autora M. Villalobos Hennesy, «Passion, Devotion, Penitencial Reading, and the Manuscript Page: 'The
} 
La espiritualidad monástica destaca sobre todo la «admiración» por la obra de la redención -expresada en términos de «adoración» más que de «imitación»- para llegar a la contemplación, al éxtasis y a la unión con Dios 6 .

Las órdenes mendicantes profundizaron en esta misma línea. San Buenaventura (1218-1274) es uno de los escritores más destacados sobre la pasión. En continuidad con la espiritualidad monacal, compuso la obra Officium de passione Domini, donde ofrece su propuesta de meditación de la pasión según las horas canónicas. Después de San Buenaventura, los relatos sobre la pasión se multiplicaron, tanto que se ha podido decir que el medievo ha tenido «pasión por la pasión del Salvador» ${ }^{7}$.

Uno de los autores más representativos, y testigo de esta devoción más allá de los monasterios y los conventos, es el obispo francés Guillermo de Durando (1230-1296), que en su Rationale divinorum officiorum asigna el prendimiento a la Vigilia; las burlas a Maitines; la entrega a los gentiles en Prima; en Tertia, la flagelación y la condena a muerte; la crucifixión, en Sexta; en Nona, la muerte; en Vísperas (decimoprimera), el descendimiento; y finalmente en Completas (decimosecunda), la sepultura ${ }^{8}$.

La devotio moderna ${ }^{9}$ siguió meditando la pasión, pero aportó una gran novedad en cuanto al método. La nueva sensibilidad humanista, por una parte, obliga al orante salir del anonimato de la oración coral para establecer una relación personal con Dios mediante la oración mental, y por otra, busca la fuente de las virtudes en el interior del hombre más que en las prácticas externas. El objetivo de la devotio moderna es la regeneración de la imagen interior de Dios en el hombre que ha quedado desfigurada por el pecado ${ }^{10}$. Esto no se

Hours of the Cross' in London, British Library Additional 37049», Medieval Studies 66 (2004): 213252, hace un estudio de este tipo de obras a partir de un manuscrito encontrado en la British Library.

${ }^{6} \mathrm{Cf}$. R. Torres Jiménez, «Notas para una reflexión sobre el cristocentrismo y la devoción medieval a la pasión y para su estudio en el medio rural castellano», Hispania Sacra 118 (2006): 449-487; en p. 485, nota 138, recoge una idea de G. Lobrichon: «No habría tanto dramatismo en el culto a la pasión; la aflicción no es tanto la del hombre, sino la de Dios» y comenta que miraban al Crucificado sobre todo como Salvador que tranquilizaba su angustia ante la condenación eterna. Cristo era ante todo el Salvador, el crucifijo «se convirtió en una imagen de adoración» y la cruz en sí era «investida por un poder espiritual directamente contenido en el objeto».

${ }^{7} \mathrm{~F}$. Vernet, La spiritualité médiévale (París, 1929), 82.

${ }^{8}$ Guillermo Durando, Rationale divinorum officiorum, V-VI. Ed. Por A. David-T.M. Thibodeau (Turnholt: Brépols, 1989). Cf. U. Köpf, «Passionsfrömmigkeit», 722-764, donde se explica además el desarrollo histórico de los «relojes de la pasión» o de la vida de Cristo.

${ }^{9}$ Cf. J. Álvarez Gómez, Historia de la vida religiosa III. Desde la «Devotio moderna» hasta el Concilio Vaticano II (Madrid, 1990), 19-51.

${ }^{10}$ Se da mucha importancia a la interioridad: un volver continuo a lo más íntimo para dedicarse a Dios y a las cosas espirituales («reditus ad interiora», «se dare ad interiora»). Mantenerse lejos del mundo y de sus peligros, en el silencio de la propia celda, es una forma de crear el ambiente interior adecuado (cf. Imitación de Cristo, 1, 20). 


\section{Jesús Pulido Arriero}

logra solo apartándose del mundo exterior del que preservaba el claustro, sino sobre todo trabajando en el interior, en el alma del hombre. La meditación hace que entren en juego y se purifiquen las tres potencias del alma progresivamente, «subiendo» de una a otra.

La devotio moderna se separa de la «scala claustralium», que seguía el «ordo scalaris realis» -es decir, «quando ex ordine rei in rebus fit ordo conceptum»-, y propone una nueva «scala meditationis», que sigue el «ordo scalaris rationalis». En este nuevo método el progreso de meditación está determinado por las partes del alma humana, aplicando, primero, la memoria, es decir, la representación de los hechos; después, la intelligentia, que profundiza en su sentido con consideraciones; y finalmente la voluntas que activa el corazón ${ }^{11}$. La «escala» de la oración en la Edad Moderna ya no mira al cielo, sino al interior de la persona: ahora el «levantamiento» del alma consiste cada vez más en su «interiorización», en un movimiento de fuera a dentro, más que de abajo a arriba ${ }^{12}$.

En España, el abad benedictino de Montserrat, García Jiménez de Cisneros ${ }^{13}$ fue el primero en componer un libro de oración metódica moderna, el Exercitatorium vitae spiritualis (1500), escrito en lengua vernácula «para que sea accesible al pueblo simple y devoto, con poco conocimiento en materia espiritual» ${ }^{14}$. La reforma de los recogidos y los descalzos en el

\footnotetext{
${ }^{11}$ Cf. K. Baier, Meditation und Moderne. Zur Genese eines Kernbereichs moderner Spiritualität in der Wechselwirkung zwischen Westeuropa, Nordamerika und Asien, I (Wurzburgo, 2009), 66: «Scala autem rationalis mea non sterilis aut infirma; sed meo iudicio ceteris praestantior instrumentis: quippe cetera quaeque complectens. Quae ideo rationalis vel interna scala dicitur, quia totis gradibus intra nos est» (J. W. Gansfort, Scala meditationis IV, cap. 3, 281).

${ }^{12}$ Las meditaciones medievales tenían un sentido filosófico más reflexivo que orante; no forman propiamente parte de la oración, como en la edad moderna. San Bernardo y san Buenaventura constituyen un paso sucesivo en esta dirección de la meditación afectiva, aunque se mantienen en las coordenadas monacales. Santo Tomás considera la meditación o «cogitatio» la antesala de la verdadera oración, que es la contemplación. J. Leclercq indica cómo este tipo de literatura que tiene por objeto la oración privada meditativa en cierta manera se inicia en el siglo XI. San Anselmo ya escribió Meditationes et orationes y Fécamps, Meditationes sancti Augustini. Cf. J. Leclercq, Preghiera nel Medioevo, en Dizionario degli Istituti di Perfezione VII (Roma, 1983), 610.

${ }^{13}$ Para estas informaciones, cf. García M. Colombás, Un reformador benedictino en tiempo de los Reyes Católicos: García Jiménez de Cisneros (Montserrat, 1955); García Jiménez de Cisneros, Obras Completas (2 vols.). Ed. Por C. Baraut (Montserrat, 1965); I. Rodríguez-Grahit, La Devotio moderna en Espagne (Ginebra 1957). Contra los que piensan que García de Cisneros pudo haber aprendido ya la oración metódica en Valladolid, C. Baraut (ibid., 11) afirma: «Resulta en extremo arriesgado pretender que a mediados del siglo XV existiera en San Benito de Valladolid una escuela ascética inspirada en las teorías y prácticas propias de la devotio moderna». No hay constancia de la presencia de la oración metódica en Valladolid hasta 1500 en que aparecen las primeras disposiciones al respecto. Cf. También G. M. Colombás, Un reformador benedictino, 174s.

${ }^{14}$ Obras completas I, 55.
} 
siglo XVI ${ }^{15}$ introdujo esta espiritualidad en los recolectorios o «casas recolegiadas» («domus recolectionis») ${ }^{16}$. Por el eremitorio de la Salceda pasaron Francisco de Cisneros, Bernardino de Laredo y Francisco de Osuna ${ }^{17}$. En la misma línea estaba el convento dominico de Escalaceli de Córdoba, del que Fray Luis de Granada fue prior ${ }^{18}$.

Melquiades Andrés sostiene que «es un hecho que [a través de estos ambientes de recolección] llegaron los libros de la devotio moderna a España» ${ }^{19}$. El mismo Melquiades Andrés afirma que entre 1480 y 1560, más allá de las escuelas o familias religiosas, se impone una espiritualidad unitaria que hace el tránsito de la concepción medieval a la moderna, interior, personal, favorecida por el nominalismo, el humanismo renacentista e incluso por la posibilidad de tener cada religioso su libro de meditación, gracias a la expansión de la imprenta ${ }^{20}$.

La necesidad de nuevos manuales de oración hizo que, poco a poco, se fueran componiendo numerosas obras en lengua vernácula: vidas de Cristo, relatos de la pasión versificados, autos de la pasión... Las publicaciones de este género fueron muy abundantes. M. Andrés Martín, en Historia de la mística en la Edad de oro en España, presenta un «catálogo incompleto» de unos 1.200 títulos entre 1485 y $1759^{21}$; J. C. Requena, en su tesis doctoral de 1997, también hace una enumeración de las obras publicadas desde 1482 en prosa y

${ }^{15}$ Cf. M. P. Aspe, «El cambio de rumbo de la espiritualidad española a mediados del siglo XVI», en A. Alcalá y otros, Inquisición española y mentalidad inquisitorial (Barcelona, 1984), 424-433; R. García Mateo, «San Juan de Ávila, maestro de oración», Anuario de Historia de la Iglesia 21 (2012): 78s.

${ }^{16}$ Las Constituciones de las órdenes religiosas introdujeron la práctica de la oración metódica, al menos de dos horas al día, «allende de lo que cada uno en particular querrá hacer». En los recolectorios la «oración mental» constituye el «fundamento en que estriba toda la vida espiritual y el medio más eficaz que puede haber para la reformación del hombre interior y exterior»: Constituciones, dist. $1^{\mathrm{a}}$, cap. 5 , f. $4 \mathrm{v}$. Cf. un buen estudio de conjunto, A. Martínez Cuesta, «El movimiento recoleto en los siglos XVI y XVII», Recollectio 5 (1982): 5-47, del que tomamos las citas. Cf. también Th. H. Bestul, Texts of the Passion: Latin Devotional Literature and Medieval Society (Philadelphia, 1996).

${ }^{17}$ Cf. M. T. Fernández Madrid-M. Gómez Lorente, «El Convento de Nuestra Señora de la Salceda. Análisis histórico y simbólico», Revista de Estudios del Marqués de Santillana 19 (1992): 431-444.

${ }^{18}$ Cf. A. Huerga, «F. Luis de Granada en Escalaceli. Nuevos datos para conocimiento histórico y espiritual de su vida», Hispania 9 (1949): 434-479; 10 (1950): 293-335.

${ }^{19}$ Cf. M. Andrés, La teología española en el siglo XVI I (Madrid, 1976), 365ss.

${ }^{20}$ Cf. M. Andrés, Los recogidos. Nueva visión de la mística española (1500-1700) (Madrid, 1975), 28-29. En esto se distancia de la tendencia a dividir la espiritualidad española del siglo XVI en escuelas religiosas, como M. Menéndez Pelayo, Historia de las ideas estéticas I (Madrid, 1974), 561-562; P. Sainz Rodríguez, Introducción a la historia de la literatura mística española (Madrid, 1984), 229-230.

${ }^{21}$ Cf. M. Andrés Martín, Historia de la mística en la Edad de Oro en España y América (Madrid, 1994), 151-207. 
verso $^{22}$. Una antología de las obras más importantes fue publicada por Pedro Sainz en cuatro volúmenes ${ }^{23}$. No han sido los únicos que han intentado elaborar una lista ${ }^{24}$ o presentar estadísticas ${ }^{25}$.

Frente a esta numerosa literatura, nosotros nos limitaremos a aquellos autores que más nos interesan para encontrar el humus común que subyace en el método de meditación de la pasión de San Juan de Ávila ${ }^{26}$. Nos detenemos únicamente en aquellos que proponen, como él, un método inspirado en la devotio moderna, y presentan una distribución semanal de la meditación de la pasión: Francisco de Osuna, Bernardino de Laredo, Pedro de Alcántara, Fray Luis de Granada, Ignacio de Loyola, proponiendo al final un cuadro sinóptico que nos permita ver su evolución. Pero antes, expongamos, como punto de referencia, la motivación de San Juan de Ávila para acentuar tanto la meditación de la pasión en su espiritualidad y el método que practica y propone en su círculo.

\section{La meditación de la pasión en San Juan de Ávila}

\subsection{Presupuestos cristológicos y soteriológicos}

San Juan de Ávila es un humanista de la Edad Moderna. Para él, el hombre es «capax Dei»: «Y considera cómo te pudiera Dios hacer piedra, o no te hacer, o hacerte bestia u otro animal que no tuviera razón. Y Dios por su bondad te hizo hombre capaz de ver y de gozar de él...» ${ }^{27}$. Para él, las potencias del «ánima», creadas a imagen del Dios trinitario, son «como vasijas»o «disposiciones» para que se llenen y pueda entrar en comunión con Él: «¿Qué lengua habrá que diga cuán bien, cuán propio, cuán ajustado viene Dios con el alma? Pues ella es criada a imagen de él, y la junta es indecible, el amor es indecible, y así lo son los deleites... según la hambre así es la hartura ${ }^{28}$. Es una idea

\footnotetext{
${ }^{22}$ J. C. Requena Moita, La espiritualidad española de los siglos XV-XVII a través de las Vita Christi (Tesis Doctoral de la Universidad de Barcelona; Barcelona, 1997), 71-134.

${ }^{23}$ P. Sainz Rodríguez, Antología de la literatura espiritual española (4 vols.) (Madrid, 1980-1985); Id., Introducción a la historia de la literatura mística en España (Madrid, $\left.{ }^{2} 1984\right)$.

${ }^{24}$ Cf. J. Sánchez Herrero, La Semana Santa de Sevilla (Madrid, 2003), 48-54; también L. Delbruge, A Scholarly Edition of Andrés de Li's Thesoro de la passion (1494) (Leiden, 2011).

${ }^{25} \mathrm{Cf}$. G. Lemeunier, «El nuevo coloquio divino. Investigaciones sobre la oración mental metódica en la literatura del siglo de oro», Revista Murciana de Antropología 2 (1997): 41-63.

${ }^{26}$ L. Sala Balust, Obras I, 171 habla de la relación del Audi Filia con el Ejercitatorio de García de Cisneros, pero estas relaciones con la literatura precedente no las vamos a considerar en este apartado.

${ }^{27}$ Tratado de anihilación, en Obras II, 1027.

${ }^{28}$ Ser 55, 59, en Obras III, 742.
} 
en la que insiste con frecuencia: «Te dio memoria, con que acordases de las mercedes que de él has recibido; y entendimiento, con que le conocieses; y voluntad, con que le amases...» ${ }^{29}$.

El hombre ha sido pensado desde el principio y creado para la comunión con Dios. Para ello, el Señor había previsto desde la eternidad la unión de su divinidad con la humanidad, mediante la encarnación del Verbo. San Juan de Ávila habla de la encarnación del Hijo en la humanidad de Jesús y de la salvación de todos los hombres como un solo movimiento del amor de Dios. Lo explica así: «Tiene Cristo dos cuerpos: uno que recibió de la Virgen y otro que somos nosotros» ${ }^{30}$. El primero, lo personaliza el Verbo eterno al modo como el alma se une a la carne, y el segundo, lo incorpora el Verbo encarnado al modo como la cabeza se une con el cuerpo. La encarnación es la unión hipostática, en la única persona del Verbo eterno, de la divinidad y humanidad, y la incorporación es la unión mística en el Verbo encarnado, de los hombres con Dios. Para el Maestro Ávila, la cristología coincide con la soteriología puesto que «salvar Cristo al hombre y rogar por él» es lo mismo que «salvarse a sí mesmo y rogar por sí mesmo» ${ }^{31}$.

En este plan originario de salvación de Dios, entró en escena el pecado del hombre que hizo todo más difícil. Para San Juan de Ávila, el pecado hace al hombre perder su disposición natural para la unión con Dios: el «gusto y facilidad» con que «se convertía y amaba a Dios» ${ }^{32}$, y hace de la vida de gracia «un continuo martirio y una molesta guerra ${ }^{33}$. El hombre descubre la gravedad de su pecado precisamente a la luz y la experiencia del don del amor de Dios que se ha manifestado sobreabundantemente en la pasión de Cristo:

\footnotetext{
${ }^{29}$ Escrito segundo, en Obras II, 1023. San Juan de Ávila desarrolla en varias ocasiones y de varias maneras el hombre creado a imagen de Dios no basándose en el Hijo sino en la Trinidad a la que presenta con la imagen agustiniana de la interioridad: Dios Padre es el ser, el Hijo la noticia, el entendimiento, y el Espíritu la voluntad. Cf. In 1 Jn (1) lec. 3, en Obras II, 118: «En la Santísima Trinidad hay tres personas y una sustancia, ansí en nosotros hay un ánima y tres potencias». Cf. también. In 1 Jn (1), lec. 15, en Obras II, 343. Más claro aún en Dialogus, 4, en Obras II, 770s: «Este Señor a quien ofendiste es un Dios verdadero, trino en personas y uno en esencia, Padre que ab aeterno, de su mesma substancia, en sí mesmo engendra al Hijo, al cual da, por modo inefable y naturalmente, toda su divinidad, y virtud, y ser, y esencia, y sapiencia, y todas sus perfecciones por la fecundidad y infinita virtud de su divino entendimiento... el cual Padre e Hijo, aunque son dos personas verdaderamente distintas, no son más que un Dios, que por su divino y infinito amor producen al Espíritu Santo, por su divina voluntad, también naturalmente, al cual así como el Padre, por el divino entendimiento, da todo el ser y bien que tiene al Hijo, así el Padre y el Hijo dan el mismo bien y ser al Espíritu santo por su divina voluntad, con que naturalmente se ama, puesto que el divino entendimiento y voluntad no es otra cosa sino el mismo ser divino...».

${ }^{30}$ AF [II] 84, en Obras I. 718.

${ }^{31}$ Ser 53, 30-33, en Obras II, 698.

${ }^{32}$ Ser 54, 4, en Obras III, 701.

${ }^{33}$ Carta 32, en Obras IV, 182.
} 
Haberse puesto Jesucristo en la cruz para librar al hombre del pecado, dejaba pintado tan feo al pecado y había de poner en tan grande espanto al hombre, que ya nunca más había de volver a cosa que tanto costó a la mesma potencia de Dios dar remedio con ella ${ }^{34}$.

Por eso, la obra salvadora de la pasión no solo mira a Dios para pedir perdón, sino que mira también al hombre para moverle y atraer su corazón al amor de Dios, elevando y respetando su libertad ${ }^{35}$.

La «redención» del pecado, no la hacen los hombres con sus fuerzas, sino que es obra de «los merecimientos de Cristo» ${ }^{36}$. Así, la santidad verdaderamente cristiana no puede consistir simplemente en un proceso de perfeccionamiento o maduración en virtudes mediante el esfuerzo personal ${ }^{37}$ : «Muchos siervos de Dios» han tomado por medio «mortificarse y alcanzar virtudes; así para alcanzar paciencia el que no la tiene procura acostumbrarse a sufrir». El camino de la pura ascesis exterior es el que siguieron los «filósofos» paganos y el que tienen que seguir los moros y judíos que no creen en Cristo.

Para los cristianos «hay otra manera de buscar virtudes, engrandecida y alabada por la Sagrada Escriptura, y es cuando el hombre, poniendo y asentando su conciencia en los merecimientos de Cristo, cree que por él ha de alcanzar lo que toca a la salvación». Sin negar la ascesis personal, «esta manera de alcanzar virtudes ha de ser la principal del cristiano ${ }^{38}$. Por eso, para alcanzar la santidad en esta vida y la salvación futura no hay nada mejor en qué ocupar la mente que meditar la pasión del Señor y a qué dedicar la vida que a imitarla, pues sería «extremo desagradecimiento poner en olvido un tan inmenso beneficio de amor como fue padecer Cristo por nos» ${ }^{39}$. Y concluye San Juan de Ávila: Aunque "hay diferentes caminos de ir a Dios, y diferentes modos de servirle, solo pienso poner uno, porque pienso que es con el que Dios mucho se contenta, que es la oración mental"40.

La oración mental, para nuestro autor, no consiste en apagar las potencias del alma sino, todo lo contrario, en un «continuo obrar con el pensamiento, andando en busca del conocimiento de Dios y de nosotros mismos» ${ }^{41}$, en tener «ilustrado el entendimiento y... la voluntad inflamada $»^{42}$. Y no solo las

\footnotetext{
${ }^{34}$ In Gal 4, en Obras II, 27.

${ }^{35}$ Cf. AF [1] I, 70, en Obras I, 437.

${ }^{36}$ Carta 222, en Obras IV, 702.

${ }^{37}$ Cf. Plática 3, 8, en Obras I, 818.

${ }^{38}$ Carta 222, en Obras IV, 703.

${ }^{39}$ AF [2] 68, 2, en Obras I, 680.

${ }^{40}$ Avisos para aprovechar en la oración, en Obras II, 1016.

${ }^{41}$ Siete nuevos escritos 1, 3, en Obras II, 1019.

${ }^{42}$ In 1 Jn (2) lec. 18, en Obras II, 421.
} 
potencias del alma, sino que «es menester todo el hombre...», también «los sentidos», pues, ya que los «tienes de Dios, justa cosa es que le sirvas con ellos» $»^{43}$.

Mediante la oración mental, el Verbo encarnado supera su contingencia histórica y se hace contemporáneo de todos los hombres ${ }^{44}$. Su pasión no es únicamente un hecho histórico del pasado, un dato de crónica, sino que tiene un valor permanente: Cristo, que «fue muerto desde el principio del mundo», sigue sufriendo pasión hasta el fin. La misma figura del Ecce Homo que Pilato «sacó entonces a los ojos del pueblo furioso, esa misma se presenta hoy a los del Padre piadoso tan fresca y tan corriendo sangre como estaba aquel día ${ }^{45}$ para obrar la salvación, y sigue mostrándose a los ojos de los hombres buscando su compasión y su conversión. Nuestro autor acentúa tanto la eficacia actual de la pasión mediante la meditación, que le concede un valor cuasi-sacramental: meditar los hechos de la pasión de Cristo es una forma de «comer su carne», es decir, de participar en su salvación, como en el sacramento de la Eucaristía ${ }^{46}$.

Aunque Cristo ya murió por todos los hombres, la meditación logra que su pasión se aplique a cada persona en concreto. Pues Dios no muestra su amor «solamente con todos los hombres en general», sino que a cada uno «le tiene en particular este amor, y por él en particular se hizo aquella obra». En la meditación actualizada de la pasión, el orante llega a sentir que, «si no pecara otro que yo, por mí solo viniera a morir ${ }^{47}$.

\subsection{Referencias a la meditación de la pasión}

A partir de estas convicciones, y basándose en su propia experiencia, San Juan de Ávila describe un detallado método de meditación de la pasión, para que el hombre se sienta atraído por el amor de Dios y alcance su gracia y su fuerza salvadora. El método es una ayuda para meditar durante dos horas cada día de la semana una escena de la pasión.

Al menos en 13 ocasiones habla San Juan de Ávila de este método, adaptándolo a diversos tipos de personas: sacerdotes dedicados a la predicación o a la confesión, religiosos, beatas, laicos, madres de familias, trabajadores...:

\footnotetext{
${ }^{43}$ Siete nuevos escritos 2, 2, en Obras II, 1026.

${ }^{44}$ Cf. AF (2) 68, 2, en Obras I, 680: «Porque su morada según el cuerpo en este destierro convenía -según la ordinación de Dios- que fuese por pocos años y en pequeña parte de la tierra... ordenó su amor que, ya subido - resucitado y glorioso- a las alturas del cielo, descendiese a la tierra, no a aquesta parte ni a aquella sino a todo el mundo universo donde hijos tuviese, y no por tiempo de treinta años, sino por todo el tiempo que el mundo durare».

${ }^{45}$ Ecce Homo, en Obras II, 766.

${ }^{46} \mathrm{Cf}$. Tratado del sacerdocio, 26, en Obras I, 93.

${ }^{47}$ In Gal 2, 20, num. 26, en Obras II, 56.
} 
1. Recomienda y habla de la meditación de la pasión en Audi Filia (1) II, núm. 46-64, en Obras I, 458-471 y en Audi Filia (2) cap. 68-81, en Obras I, 680-714, que es como una ampliación de la formulación anterior. En ambas ediciones de la obra principal de San Juan de Ávila se encuentra el contenido fundamental. Fray Luis de Granada se había referido a la edición de 1556 como «cuanto podía recomendarse en esta materia» ${ }^{48}$. La edición póstuma del Audi Filia no solo no eliminó nada, sino que ha convertido el tema en un verdadero tratado sobre la oración ${ }^{49}$.

2. En Dialogus inter confessarium et paenitentem num. 20, en Obras II, 782 (respondiendo a la pregunta «¿cómo os va acerca de la oración?»), recomienda de nuevo la meditación de la pasión, y ofrece la reglamentación de la misma en cuanto a tiempos y método.

3. En Reglas muy provechosas para andar en el camino de nuestro Senor, 6 (Obras II, 845), en las que, para «recibir y conservar la gracia del Espíritu santo», junto a la confesión, la práctica de los sacramentos y al cambio de costumbres, recomienda pensar cada día «algún paso de la pasión de Cristo».

4. En Diez documentos ${ }^{50}$, 2, en Obras II, 849, lo primero que recomienda para ordenar la vida cristiana es la «memoria» de Cristo y particularmente la meditación de la pasión «cada mañana», junto a la oración de aniquilación, la práctica de los sacramentos, el cumplimiento de los mandamientos, la caridad con el prójimo...

5. En Carta a Francisco Guzmán, en Obras II, 1034, propone un horario tipo para una persona devota que tiene la posibilidad de dedicar todo el día a Dios: prevé la meditación de la pasión durante una hora en la mañana, seguida de un tiempo de estudio y la misa. Solamente después de misa está previsto el rezo de las Horas de prima a nona, todas juntas, hasta la comida. Se trata de avisos para una persona retirada, pero no ya en el monasterio, sino en su propia casa.

6. En el Sermón 23, domingo 17 después de pentecostés, 14, en Obras III, 283 , presenta como «remedio para amar a Dios» la meditación de la pasión. Como «fuego con fuego se enciende... discurriendo con devoción por lo que Jesucristo pasó por nosotros, encenderse ha nuestro amor para amarle».

\footnotetext{
${ }^{48}$ Cf. Obras I, 384.

${ }^{49}$ Seguramente fuera lo último que añadió al Audi Filia, pues al concluir el tema de la meditación de la pasión dice que «tenía deseado y pensado de proseguir esta materia más largo, y pasar a la consideración de la Divinidad por el escalón de la santísima Anima de Jesucristo nuestro Señor, y mi poca salud no da lugar, no os digo más» (AF [2] cap. 81, 3, en Obras I, 712).

${ }^{50}$ Se trata de una corrección a la Breve Regla de vida cristiana publicada con la edición del Audi Filia de 1556. Cf. Obras II, 848.
} 
7. En el Sermón 37, 4-12, en Obras III, 490-493, hace una comparación sugerente entre la procesión del Corpus y los «pasos» de la pasión de Cristo. Se trata de «honrar y solemnizar» la pasión mediante una representación de la misma, como se hace «en las siete horas canónicas» y en «el santo sacrificio de la misa» con «el ara y altares y vestiduras sacerdotales», es decir, «representando todo y significando muy en particular la muerte del Señor y sus circunstancias de ella».

8. En el Sermón 58 de la Octava del Corpus, 23, en Obras III, 794, recomienda la meditación de la pasión como un medio para prepararse a hacer una buena comunión.

9. En el Sermón 78 de San Francisco de Asís, 27, en Obras III, 1058, explica la identificación de San Francisco con Cristo por el pensamiento de la pasión y da consejos al oyente para que medite la pasión.

10. En la Carta 1, en Obras IV, 12s, a un predicador, probablemente a Fray Luis de Granada, enseña cómo se debe recomendar la meditación de la pasión y da los consejos para que la realicen los que «quieren servir al Señor».

11. La Carta 5, en Obras IV, 35s, lleva fecha del 2 de enero de 1538 y probablemente está dirigida al Maestro García Arias, al que propone un horario para organizar el día. Tras los maitines, recomienda meditar la pasión «tomando cada día un paso, porque no ande vagueando» durante «casi dos horas». También aquí se recomienda la meditación de la pasión por la mañana antes e independientemente del rezo de «prima, tercia y sexta». Más que con las Horas canónicas, la pasión está en estrecha relación con la misa, a la que se tiene que «aparejar» «pensando en este profundísimo misterio» que meditó anteriormente. Se trata de una persona dedicada a servir a Dios, que tiene tiempo para preparar sus predicaciones y por la tarde, tras rezar «nona, vísperas y completas», puede dedicarse a visitar enfermos y hacer obras de caridad.

12. La Carta 225, en Obras IV, 725 ss., tiene muchas coincidencias con la Carta 5. Va dirigida a un discípulo de Córdoba, quizás Alonso de Molina, que más que un predicador, podría ser un confesor de religiosas con menor formación que el destinatario de la Carta $5^{51}$. También a éste le propone un plan para organizar la jornada. De madrugada, le pide dedicar una hora a la meditación de la pasión ayudándose de «algún libro devoto». También durante la misa ha de llevar «a Cristo conforme a aquel paso que de él pensó aquel día». Por la tarde puede ir a confesar, a hacer obras de caridad o de esparcimiento.

13. La Carta 236, en Obras IV, 752ss., probablemente está dirigida a una persona que tiene sus «negocios» y a la que pide una hora de meditación sin hacer referencia alguna al rezo de las Horas canónicas. Como en las cartas

\footnotetext{
${ }^{51}$ Cf. Obras I, 67s.
} 
anteriores para sus discípulos predicadores o confesores, que viven solos pero siguen el ritmo de la liturgia de las Horas, pone un horario diario para esta persona que vive en medio del mundo.

\subsection{Líneas principales del método de meditación}

Al iniciar la meditación, hay que hacer una preparación interior, poniéndose en presencia de Dios y pidiendo perdón por los pecados, para continuar con alguna oración vocal que comunique al orante devoción.

Después, el Maestro Ávila propone hacer una lectura del «relato» de la escena de la pasión, correspondiente a ese día de la semana. Esta lectura no está tomada directamente de la Escritura, sino de algunos comentarios espirituales. Se trata, por tanto, de lecturas meditadas; no de lecturas bíblicas. Aunque San Juan de Ávila no ha desarrollado en sus escritos el contenido de cada una de las meditaciones diarias, sí podemos encontrar en sus obras indicaciones dispersas sobre cada uno de los pasos; y en ocasiones algunos pasajes suficientemente amplios ${ }^{52}$. Sin embargo, con frecuencia remite a otros libros para realizar la «lectura» de la escena de la pasión de cada día. En la Carta $1^{53}$, recomienda la Passio duorum ${ }^{54}$, como «libro en romance» acomodado para la lección junto a Contemptus mundi, la parte 2. ${ }^{\mathrm{a}}$ y 5. ${ }^{\mathrm{a}}$ de los Abecedarios espirituales de Osuna, la Vita Jesu Christi del Cartujano, la Opera Bernardi y las Confesiones de San Agustín. Específicamente para la meditación de la pasión, en la Carta $5^{55}$, vuelve a recomendar la Passio duorum junto a la primera parte del Abecedario espiritual. También la Carta $236^{56}$ recomienda la Passio duorum, junto a los escritos de Fray Luis de Granada («El Libro de la oración y meditación») sobre la pasión para «saber la historia cómo pasó». En el cap.

\footnotetext{
${ }^{52}$ Por ejemplo, sobre el Ecce homo apropiado para el miércoles: AF (1) VI, 23-32, en Obras I, 524530; sobre la eucaristía en la meditación apropiada para el jueves: Ser 37 sobre las procesiones de la pasión y la procesión del Corpus (Obras III, 489-512); Ser 38 sobre «Haced esto en mi memoria» y la relación de la eucaristía con la pasión de Cristo (Obras III, 513-523); Ser 45 al 47 (Obras III, 895913) sobre la carne de Cristo y la comunión; sobre la Virgen María, apropiado para el sábado: Ser 67 sobre la soledad de María (Obras III, 895-913).

${ }^{53}$ Carta 1, en Obras IV, 12.

${ }^{54}$ La Passio duorum (1526), atribuida a Francisco Tenorio, es citada con frecuencia por San Juan de Ávila. Se trata de un buen ejemplo de la influencia del Dialogus B. Mariae et Anselmi de Passione Domini en España. El subtítulo explica claramente su contenido: "Tratado de devotísimas y muy lastimosas contemplaciones de la pasión del Hijo de Dios; y compasión de la Virgen Sancta María. Por esta razón llamado Passio duorum». La acción se desarrolla en cinco días: desde el lunes santo, presentando a Jesús predicando en Jerusalén, hasta el viernes santo con la sepultura. Cf. J. A. Boon, «The Agony of the Virgin: The Sorrows and Crucifixion of Mary in Sixteenth Century Castilian Passion Traetises», Sixteenth Century Journal 38/1 (2007): 3-25.

${ }^{55}$ Carta 5, en Obras IV, 38.

${ }^{56}$ Carta 236, en Obras IV, 754.
} 
74 de Audi Filia (2) ${ }^{57}$, vuelve a proponer las obras de Fray Luis de Granada, esta vez junto a «las Meditaciones de San Agustín, en latín» y la Vita Jesu Christi del Cartujano.

Tras la lectura de la escena correspondiente de la pasión, San Juan de Ávila propone cuatro escalones de profundización, de fuera adentro, para acompañar a Cristo en su pasión, poniendo en juego todas las potencias del hombre.

El primer escalón es sin duda el más novedoso y propio de nuestro autor: el ejercicio de los sentidos. Se trata de re-evocar el «paso» apenas leído propiciando una participación física, sensorial del orante en lo que está pasando: san Juan de Ávila invita a ver los colores, a sentir los olores, a oír lo que dicen los personajes e incluso a participar en el diálogo, a tocar a Cristo, sus llagas... a meterse dentro de la escena físicamente:

Mirad a este hombre (...), porque en él hallaréis cuantas colores quisierdes...; bermejo de las bofetadas que recientes le han dado, y colorado de las que rato ha, y en la noche pasada, le dieron; amarillo, con la abstinencia de toda la vida y trabajos de la noche pasada; blanco, de las salivas que en la cara le echaron; denegrido, de los golpes que le habían magullado su sagrada cara; las mejillas hinchadas, y de cuantos colores las quisieron pintar los sayones (...) ¡Qué matices, qué aguas, qué blanco, qué colorado hallaréis aquí! ${ }^{58}$.

Para realizar este ejercicio, pueden ser útiles algunas reproducciones iconográficas que ayuden al orante a representar los hechos y participar en ellos. Para el Maestro Ávila, los sentidos no son «puertas del pecado», sino puertas abiertas a la experiencia de Dios. Los frutos de este escalón son compasión y sentimiento, incluso en la parte afectiva y con lágrimas.

El segundo escalón pone en movimiento el pensamiento, que vuelve otra vez sobre el «paso» del día con «devotas consideraciones» para sacar de él dolor de los pecados, virtudes con las que Cristo vivió su pasión y fuerza necesaria para imitarlas en la propia vida. Son numerosas las consideraciones que San Juan de Ávila propone al orante: sobre el dolor físico de Jesús en cada parte de su cuerpo, sobre el sufrimiento que le causaban los pecados...:

En cada paso o misterio considerad, lo primero, quién padece, y de quién, y por quién padece, para que os espantéis y admiréis de tal misterio; segundo, cuántos dolores, penas, escarnios, para que compadezcáis, y os doláis, y sintáis con él; tercero, cuán grande beneficio recibís, para que lo agradezcáis; cuarto, el modo: con qué humildad, mansedumbre, paciencia, obediencia, para que le imitéis; quinto, el amor con que padeció, para que le améis, y aquí haced gran fuerza, etc.; sexto, cuánta necesidad teníades de su pasión, cómo la tomó

\footnotetext{
${ }^{57}$ AF (2) 74, en Obras I, 694.

${ }^{58}$ AF (1) VI, 31, en Obras I, 528.
} 


\section{Jesús Pulido Arriero}

congruente y proporcionada a vuestra necesidad; séptimo, cuántos frutos salieron de aquel árbol de vida (...); octavo, cómo se nos aplica aquella santa pasión por los santos sacramentos, y por la penitencia, y por las buenas obras; noveno, cuántos y cuán innumerables hay en el mundo que por no creerla los infieles, y los malos cristianos por no recibir los santos sacramentos, y por no hacer penitencia y enmendar sus vicios, y por no hacer buenas obras, pierden tan infinito tesoro; décimo, pensad el Cuerpo místico de Cristo, que son sus escogidos, cómo fueron todos crucificados, porque, desde Abel justo y Adán, todos los que piadosamente quieren vivir en Cristo nuestro Señor padecen trabajos y persecuciones; undécimo, desead ser mártir e imitar al Señor y a los suyos, y considerad, cuando los mártires estaban para padecer, de qué manera se aparejaban para el martirio, y pedid al Señor que os dé aquel mismo espíritu; duodécimo, imaginad que están los verdugos esperando que acabéis la oración para martirizaros, y de la manera que os aparejaríades para morir por Cristo. De esta manera salid de la oración, y así ofreced al Padre encorporado con Cristo y con sus santos, y ofreced aquella pasión por vuestros pecados y por los del mundo, y rogad por todos los amigos y enemigos vuestros, etc. ${ }^{59}$.

Este escalón tiene como fruto, sobre todo, la imitación de las virtudes de Cristo. El tercer escalón, el «ejercicio del amor perfecto», pone en movimiento la voluntad del hombre para que, volviendo de nuevo sobre el mismo «paso», descubra «el amor de su sacratísimo Corazón», que es mucho mayor que los sufrimientos de la pasión y las virtudes con que los sufría:

Después de haber entrado en la primera sala exterior del templo del verdadero Salomón, que es considerar a Cristo en lo exterior, y después de haber, con el cuchillo de la divina palabra, sacrificado vuestras irracionales pasiones, que es el oficio que se hacía en la sala del Templo que se llama Sancta, resta, si hemos de proseguir el camino, que procuremos entrar en el Sancta Sanctorum (...) el corazón de Jesucristo nuestro Señor ${ }^{60}$.

Se trata de una meditación «para alcanzar amor», que culmina en la unión de la voluntad del orante con la voluntad de Dios, «cuando un ánima... desprecia lo próspero y adverso del mundo» ${ }^{61}$, y «tiene por muy gran merced y galardón el padecer por su Dios», entonces tiene «el verdadero y perfecto amor del Señor crucificado» ${ }^{62}$.

Todavía apunta nuestro autor un cuarto escalón que consiste en pasar de la humanidad de Cristo a su divinidad, de la mirada al Verbo encarnado a la contemplación del Verbo eterno:

\footnotetext{
${ }^{59}$ Dialogus, 19, en Obras II, 782.

${ }^{60}$ AF (2) 78, 1, en Obras I, 704.

${ }^{61}$ AF [2] 29, 1, en Obras I, 598.

${ }^{62} \mathrm{AF}$ [2] 27, 3, en Obras I, 596.
} 
Tenía deseado y pensado de proseguir esta materia más largo, y pasar a la consideración de la divinidad por el escalón de la santísima ánima de Jesucristo nuestro Señor, y [como] mi poca salud no da lugar, no os digo más, porque lo que aquí escribo es lo postrero de este tratado ${ }^{63}$.

Es un escalón que no llega a desarrollar totalmente, pero las pocas indicaciones que da son preciosas sobre la implicación de la Trinidad en la pasión, pues «aunque en sí la divinidad no recibió lesión ninguna, no es posible, mas verdaderamente se dice de Dios que murió» ${ }^{64}$.

La finalidad que San Juan de Ávila pretende con cada uno de estos escalones es el encuentro con Dios, que se puede dar en cualquier momento del proceso. El método consiste en «echar leña», para que el alma con sus facultades «no esté dispersa», pero, si llega la «comunicación» divina, esa «secreta e interior habla con que el ánima se comunica con Dios» ${ }^{65}$, se ha de detener en cualquier momento que se encuentre. Por tanto, la «oración mental» trata de disponer al orante a «estar colgado de Dios esperando sus mercedes» ${ }^{66}$.

\section{La meditación de la pasión en el siglo XVI}

Como decíamos al principio, San Juan de Ávila no es el inventor de este método de meditación. En el contexto de la primera mitad del siglo XVI español, la meditación de la pasión de Jesucristo fue el centro de interés de otros muchos autores espirituales españoles ${ }^{67}$. Cabe destacar entre los más cercanos a San Juan de Ávila: Francisco Tenorio (?), Passio duorum (Sevilla 1526); Francisco de Osuna, Primera parte del libro «Abecedario espiritual», que trata de las circunstancias de la sagrada pasión del Hijo de Dios (Sevilla 1528); Sexta parte del «Abecedario espiritual», que trata de las llagas de Jesucristo (Medina del Campo 1554); Luis de Montoya, Meditación de la pasión para las siete horas canónicas (Medina 1534); Pedro Sánchez Ciruelo, Contemplaciones sobre la pasión (Alcalá 1534); Alonso de Orozco, Tratado de la pasión (Madrid 1534); Monte de contemplación (Sevilla 1544); Soliloquio sobre la pasión de Nuestro señor Jesucristo (Sevilla 1551); Bernardino de Laredo, Subida al Monte Sion (Sevilla 1535); Domingo de Valtanás, Meditación de la pasión según las siete horas canónicas (Sevilla 1535); Antonio de Gueva-

\footnotetext{
${ }^{63} \mathrm{AF}(2) 81,3$, en Obras I, 712s.

${ }^{64}$ In 1 Jn [2] lec. 22, en Obras II, 439.

${ }^{65}$ AF [2] 78, 2, en Obras I, 704.

${ }^{66}$ Plática 3, 14, en Obras I, 820s.

${ }^{67} \mathrm{R}$. Ricard, «El tema de Jesús crucificado en la obra de algunos escritores españoles de los siglos XVI y XVII», en id., Estudios de literatura religiosa española (Madrid, 1964), 226-240
} 
ra, Monte Calvario (Salamanca 1542)... Estos autores son representativos de prácticamente todas las órdenes religiosas: carmelitas, franciscanos, agustinos, jesuitas... Al contrario de lo que sucedía en las escuelas teológicas, todos ellos, aun siendo de diversas órdenes, privilegiaban en su espiritualidad la devoción a la pasión de Jesús.

Como ya hemos dicho, nosotros nos limitaremos a presentar aquellos que ofrecen un método inspirado en la devotio moderna y una distribución semanal -ya no siguiendo las horas canónicas- de la meditación de la pasión para compararlos seguidamente con la propuesta de San Juan de Ávila.

\subsection{Autores espirituales más cercanos a San Juan de Ávila}

\section{Francisco de Osuna}

Quizás el primer codificador del recogimiento español haya sido el franciscano Francisco de Osuna (1492-1542) ${ }^{68}$. Sus Abecedarios espirituales (15271530) se ocupan de los elementos fundamentales de la vida recogida, que describe así:

En tres cosas ya dichas está la perfección del hombre, que son meditar la pasión del Señor [objeto del primer Abecedario]; y lo segundo casarse e tomar por mujer la oración [segundo Abecedario]; lo tercero en venir a la bienauenturança de los viadores que es andar en uia vnitiua de caridad vigilante con su Dios lo qual se alcança como fruto de las dos primeras [teología mística o recogimiento, Tercer Abecedario]. Estas tres cosas tratan nuestros abecedarios ${ }^{69}$.

El objetivo de la oración de recogimiento es «buscar a Dios dentro en nosotros mismos» ${ }^{70}:$ :O cosa maravillosa que no quiso el Señor mandarnos que los buscassemos en Roma o en Jerusalén donde el conuersó y anduuo sino en nuestro

${ }^{68}$ Cf. J. J. Morcillo Pérez, introducción a F. de Osuna, Primer Abecedario espiritual (Madrid, 2004), 21-115. Francisco de Osuna nació en Sevilla en 1492, ingresó en el convento franciscano de Alcalá donde realizó estudios universitarios. Estuvo en el convento de La Salceda, donde elaboró su método de recogimiento. Escribió seis Abecedarios: el primer y segundo sobre la oración y la meditación de la pasión; el tercero sobre la teología mística; el cuarto sobre el amor divino; el quinto sobre virtudes y medios ascéticos; el sexto sobre las llagas de Cristo. Cf. M. Andrés Martín, Los recogidos. Nueva visión de mística española (1500-1700), 107-167.

${ }^{69}$ F. de Osuna, Primera parte del libro llamado Abecedario spiritual (Sevilla, 1528), f. 3r.

${ }^{70}$ F. de Osuna, Tercer Abecedario espiritual, 483. Continúa el texto: «Unos buscan a Dios con los pastores en el pesebre por humildad y pobreza, otros con los reyes preguntan a los letrados siguiendo el estudio de la Sagrada Escritura, otros con nuestra Señora van al templo a lo buscar por oraciones y ofrendas; otros lo buscan en la cruz de penitencia, con el buen ladrón; otros lo buscan peregrinando en romerías, como los dos discípulos a quien se mostró en forma de peregrino... aunque todas las maneras ya dichas y otras semejables de buscar a Dios sean muy buenas, empero la que me parece mejor es buscarlo hombre en su corazón dentro de sí». 
coraçón que es cosa mas cercana a nosotros» ${ }^{71}$. En «la escalera, que es la orden de las cosas criadas», el alma del hombre constituye la cúspide, por eso es el lugar más adecuado para buscar al Creador y, en ella, los movimientos de la oración «suben al conocimiento del Criador y abajan al conocimiento de sí mismos» ${ }^{72}$. Osuna prácticamente identifica la conversión con llenar el alma de Dios mediante la meditación:

Lo que más deves convertir a Dios es el ánima con sus tres potencias: que la memoria piense sus cosas, y el entendimiento sea solícito en las considerar y la voluntad se deleyte en aquesto, y que estas tres potencias no se desvíen de Dios, pues que siendo trino todo se occupa en te hazer mercedes ${ }^{73}$.

El Primer Abecedario espiritual, como acabamos de indicar, «trata de las circunstancias de la sagrada passion del hijo de Dios»; sus fuentes son el Rosetum de Jean Mombaer; las Meditationes Vitae Christi, de Juan de Caulibus; el Arbol de la vida crucificada de Jesús de Ubertino de Casale; la Vida de Cristo de Ludolfo de Sajonia ${ }^{74}$. En Osuna no aparece ya la distribución de la pasión en las horas canónicas, pero tampoco llega a distribuir propiamente a lo largo de la semana las escenas concretas de la pasión ${ }^{75}$, aunque recomienda su meditación diaria, dando indicaciones para el tema de cada día: «Siquiera un rato en el día no dexes de pensar en la bendita passion (...) determina con rigor de meditar cierto tiempo en tal ora y aquel firme propósito te valdrá mucho» ${ }^{76}$. Osuna ve toda la vida de Cristo desde su pasión ${ }^{77}$ y en la descripción de ésta acentúa exageradamente el dolor, hasta un nivel que solo la divinidad y no la humanidad podría soportar: Jesús en la cruz sintió un dolor corporal mayor

\footnotetext{
${ }^{71}$ F. de Osuna, Primera parte del libro llamado Abecedario spiritual, f. 8r.

${ }^{72}$ F. de Osuna, Tercer Abecedario espiritual, 89. Cf. R. F. Pérez García, «Formas interiores y exteriores de la religión en la baja Andalucía del renacimiento. Espiritualidad franciscana y religiosidad popular», Hispania Sacra 124 (2009): 599 (587-620).

${ }^{73}$ F. de Osuna, Quinta parte del abecedario espiritual (Burgos, 1542), letra O, f. 75v; las mismas ideas son reiteradas, por ejemplo, en el Segundo Abecedario espiritual, f. 182v, y en el Sexto, f. 8r; cf. M. Quirós García, «El itinerario del recogimiento en la quinta parte del Abecedario espiritual de Francisco de Osuna. Aspectos doctrinales y léxicos», Revista de Lexicografía 5 (1998): 115-156.

${ }^{74}$ Sobre la influencia en Osuna, cf. F. de Ros, Un maître de Sainte Thérèse: Le Père François d'Osuna. Sa vie, son cuvre, sa doctrine spirituelle (París, 1936), 283-288.

${ }^{75}$ El tema de la pasión lo trata también en otras obras, como Gracioso convite, f. 105v-108r, el Segundo Abecedario Espiritual, en los tratados VI, X y XVII; además de las obras de Osuna publicadas tras su muerte, como el Quinto Abecedario, en el que propone ya un incipiente ritmo semanal en la oración: meditar todos los miércoles sobre la muerte de Cristo y los viernes en su pasión (cf. F. de Osuna, Quinta parte del abecedario espiritual, f. 76v-77v); el Sexto Abecedario, dedicado a las llagas de Cristo, o el sermón sobre la pasión que forma parte de su Trilogium evangelicum.

${ }^{76}$ Francisco de Osuna, Primera parte del libro llamado Abecedario spiritual, f. 14r; f. 45v.

77 «Toda la vida del Señor fue cruz y tormento» (ibid., f. 30v).
} 
que el de un parto ${ }^{78}$, en el huerto de Getsemaní sudó más sangre que tiene un cuerpo humano ${ }^{79} \ldots$ Las descripciones retóricas de los distintos momentos de la pasión usan profusamente la imaginación que aporta infinidad de comparaciones, siempre que no entren en contradicción con el texto de los evangelios. Así, compara al «Ecce homo» con un toro, «pues que a los toros echan puas y dessuellan los animales (...) y tus espinas se dizen ser como las puas que ponen en las garrochas para correr los toros ${ }^{80}$. La flagelación le lleva a describir el cuerpo de Cristo «peor que de leproso hecho manantial de sangre (...)». En la crucifixión describe con detalle cómo los clavos desgarran su carne ${ }^{81}$.

En cuanto a los frutos de este ejercicio, la meditación de la pasión, como en la piedad franciscana, lleva a la imitación de Cristo y al crecimiento en virtud: «Contemplar la pasión tiene que servir como la luna hace de noche y la imitación como el sol hace en el día». Francisco de Osuna pone al lector ante un «espectáculo visual» para provocar en él conmoción y para que llegue a sentir, más que a comprender, la gravedad de lo ocurrido: ${ }^{i} \mathrm{O}$ que escozimiento y dolor...! Lástima grande era verlo...». Este «sentimiento» es una invitación a la imitación, que a veces consiste incluso en tener los mismos padecimientos de Cristo para comprender lo que sufrió Cristo por los hombres: «Toma un açote y disciplínate para que sientas en ti lo que sentiría el Señor en sus pasiones e tormentos ${ }^{82}$. Pero, además de la imitación, queremos destacar también otro fruto en este autor: el valor salvífico que adquiere la meditación de la pasión. El fin de la pasión que era la salvación de los hombres («todos sus dolores fueron por vernos nacidos a nueva vida de gracia ${ }^{83}$ ) se alcanza mediante su meditación, que «es el colirio y unción con que deues untar los ojos de tu anima para que veas» ${ }^{84}$.

\footnotetext{
${ }^{78}$ Aspirar a sufrir un dolor mayor que el del parto durante la meditación de la pasión de Cristo es un lugar común vinculado a la pasión en la Edad Media. Cf. J. Huizinga, El otoño de la Edad Media (Madrid, 1990), 269.

${ }^{79}$ Cf. Francisco de Osuna, Primera parte del libro llamado Abecedario spiritual, f. 28r: «el devoto puede meditar como el Señor padeció todos sus miembros y divino cuerpo». El tratado 16 contiene «una devota meditación de los miembros del Señor» en la que repasa cada uno de sus miembros en la cruz: la cabeza y los cabellos, ojos y nariz, «preciosa boca» y dientes, «lengua del Salvador», mejillas, faz y barbas, cuello, hombros, brazos, manos, pecho, «sagrado costado».

${ }^{80}$ Francisco de Osuna, Primera parte del libro llamado Abecedario spiritual, f. 74v.

${ }^{81}$ Cf. ibid.: «(...) como enclauassen con gruesos clavos en distantes agujeros las benditas manos del Señor, y como estando con cordeles estiradas, los pies no alcançassen al lugar donde auian señalado, leuantaron en alto la pesada cruz y dexaronla caer... para que estando el Señor alto pudiessen tirar de los pies mejor para que alcançassen, y esto hecho ató el uno de los sayones un cordel a los sanctos pies y otro puesto en una escalera tomó un martillo y un gruesso clavo mas que los otros, y estándolo hincandolo en los sagrados pies, por la sangre que dellos corría resualósele el martillo de las manos (...)».

${ }^{82}$ Ibid., f. 46r.

${ }^{83}$ Francisco de Osuna, Primera parte del libro llamado Abecedario spiritual, f. $26 \mathrm{v}$.

${ }^{84}$ Ibid., f. 28 r.
} 


\section{Bernardino de Laredo}

Bernardino de Laredo (1482-1540) ${ }^{85}$ probablemente es el mejor exponente del recogimiento en su obra Subida del Monte Sion (1535) y el que más ha influido en los místicos españoles del siglo XVI ${ }^{86}$. Divide su obra en tres partes que corresponden a los tres pasos para lograr la oración recogida y señala meditaciones diarias para cada uno de ellos en ritmo semanal ${ }^{87}$ : el primer paso es la «anichilación» -la purificación de los sentidos viendo que «lo que el hombre puede obrar en su inquisición es en verdad casi nada por sí» ${ }^{88}$-, cuya meditación «tiene lugar y tiempo señalado, dende rezados los maitines hasta prima»; el segundo paso es la meditación de los misterios de la vida de Cristo, «dende prima a nona»; y finalmente, el tercer paso consiste en la «recolección», que describe como «no pensar nada», «la quieta unión con Dios», «dende nona hasta la hora de maitines, el espacio que velamos» ${ }^{89}$. La «recolección» no mira ya arriba, al cielo, sino al interior, y consiste en «la transformación de sí mismo en Dios mediante el amor», que se consigue con la «redirección», el repliegue de las potencias del alma -normalmente atentas

\footnotetext{
${ }^{85}$ Fray Bernardino de Laredo, «Subida al Monte Sion», en Místicos franciscanos españoles (Madrid, 1968), 28-442 (las citas las tomaremos de esta edición). Cf. M. Andrés, La Teología española en el siglo XVI II (Madrid, 1977), 214-218; T. H. Martín, introducción a «Via Spiritus» de Bernabé de Palma / «Subida del Monte Sion» de Bernardino de Laredo (Madrid, 1998), pp. XXX-XLIII; Bernardino de Laredo, Subida del Monte Sion. Ed. A. Alonso González, M. García Trascasas y B. Gutiérrez Rodilla (Madrid, 2000); M. de Castro, OFM, s.v. Laredo, Bernardino de, en Q. Aldea (dir.), Diccionario de Historia Eclesiástica de España II (Madrid, 1972), 1269.

${ }^{86} \mathrm{Cf}$. M. Andrés, La teología española en el siglo XVI II, 214ss., indica que el título y la materia de esta obra recuerdan a la Subida del Monte Carmelo de san Juan de la Cruz, que leyó sin duda la obra de Laredo. También influyó en santa Teresa, que lo utiliza para explicar a sus confesores el modo de su oración. Además, metáforas como la del castillo, la mariposa, la abeja, etc., empleadas por santa Teresa, están también tomadas de esta obra. Finalmente, indica que santa Teresa lo usa como fuente para la formulación del lenguaje interior y pone como ejemplo el Libro de la Vida, cap. 23, 11-12. Cf. también J. A. Boon, The Mystical Language of Recollection: Bernardino de Laredo and the 'Subida al Monte Sion'(Tesis Doctoral; Universidad de Pensilvania, 2004).

${ }^{87}$ Bernardino también conoce el ritmo diario de los monjes e incluso lo rescata: «Quando tañe las horas, recoja en el pensamiento lo que aquella hora significa; conviene a saber: la prisión en los maitines; en la prima el discurso ante los jueces, a la tercia la columna; a la sexta la corona; a la nona, la cruz; a las vísperas el descendimiento della; a las completas, la sepultura o monumento». Pero no solo las horas del día para la pasión sino también las diversas acciones del día cobran un significado para la propia «aniquilación»: «oyendo la voz del que despierta a maitines, represente en la memoria la trompeta: Levantaos, muertos, al juicio... cada vez que se acostare a dormir, quan presto y cierto será echarle en la sepultura (...) cada vez que se sentare a comer, ponga a su cuenta el escote de la comida primera (el pecado de Adán) (...) cada vez que ha de beber se acuerde que bebió Cristo en la cruz vinagre y fiel». Para las citas, cf. supra, la edición de las obras de T. H. Martín.

${ }^{88}$ Subida al Monte Sion, parte II, cap. 13, en Místicos franciscanos españoles, 200.

${ }^{89} \mathrm{Ibid}$., part I, reglas, en Misticos franciscanos españoles, 31.
} 
al exterior, a las cosas creadas- hacia el interior, para encontrar a Dios en el centro del alma ${ }^{90}$.

La meditación de la pasión de Cristo forma parte del tercer paso, de la «recolección». Es decir, se trata ya de una actividad del alma dentro de sí misma. Por eso, no es solo una meditación visual o exterior, sino que tiene una técnica psicológica más depurada al servicio de la introspección:

Contemplando los misterios altísimos de Cristo (...) no vaya el ánima a ver aquellos misterios al lugar donde acaecieron, mas que el lugar y el misterio lo atraiga y lo meta en sí misma, recogiéndose toda dentro, porque en su mismo corazón tiene anchuras y lugar para cuanto tiene en él $(. . .)^{91}$.

No consiste, pues, simplemente en entrar a formar parte de la escena como testigo presencial de un acontecimiento pasado, sino en acoger y reproducir en el espacio interior del alma la pasión de Cristo:

Y aquello se entiende así, que si piensas en los azotes de Cristo Iesus (...) que pensando en sus azotes, sea tu corazón columna. De manera que de golpe o recudida no puedas sentir ni pensar en algún açote o golpe que no toque en tu columna (...). Item si piensas en la coronación, sea tu corazón la silla o sea la púrpura, y no haya alguna espina que no toque o lastime o te ensangriente los ojos (...). Y si piensas en la cruz, sea tu corazón la piedra en que fue hincada; y aún lo más tierno e interior sea el agujero della, de manera que la sangre que corría por el madero lave tu dura sustancia... y así en todos los misterios $(. . .)^{92}$.

Bernardino de Laredo describe el interior del alma en términos espaciales, como un ancho mundo («no ha lugar decir que es estrecho el corazón, porque más puede caber en él y en el largo entendimiento»). Y el recogimiento consiste en entrar en ese espacio interior («éntrate en ti y a ti traerás los misterios, y todos cabrán en ti, y tú serás tierra santa»), donde «si te sabes encerrar (...) dentro hallaremos al muy benigno Dios, espejo clarísimo, en el cual vernos a todo nuestro querer todo quanto ver queremos». Conseguir «que el alma esté dispuesta y purificada en todo lo que es en sí» es el objetivo de la meditación de la pasión, que «es quien más puede ayudar en

\footnotetext{
${ }^{90}$ Así, las tres partes de su obra forman una progresiva interiorización: «La meditación de nuestra anichilación es por vía de inquisición y discurso de entendimiento, y la contemplación de los misterios de Cristo, entrañas suavísimas del ánima desterrada, son y han de ser por inquisición de entendimiento y recepción de voluntad. Así que lo primero se ha de buscar en lo exterior, que es las cosas de fuera pensando quién hemos sido y quién somos (...) Y lo segundo se ha de buscar también en lo exterior, y ha de permanecer dentro. Mas el punto tercero que es la quieta contemplación de cosas incorpóreas, puro espíritu y del altísimo Dios, esto ha de ser totalmente por modo de recepción (...)» (Prefacio).

${ }^{91}$ Subida al Monte Sion, parte II, cap. 13, en Místicos franciscanos españoles, 199.

${ }^{92}$ Ibid., 200.
} 
esta negociación» ${ }^{93}$. La meditación de la pasión es «perfectísima escuela que lleva el alma más que otra doctrina a la alta contemplación de las cosas incorpóreas» ${ }^{94}$. Los frutos de la meditación son «conciencia limpia y anima desocupada y entendimiento ordenado y voluntad determinada», para «esperar la divina dignación» ${ }^{95}$.

Bernardino de Laredo ofrece diversas meditaciones sobre la pasión para cada día de la semana: los cap. 17-27, que tratan de Getsemaní, el proceso, la flagelación, el vía crucis y la crucifixión, son para los primeros días de la semana; el viernes «siempre sea la licción que representa la dignidad de la cruz» (en el cap. 31); al sábado le corresponden los cap. 33 y 34 sobre la estancia en el limbo durante tres días; y al domingo el cap. 35 sobre la resurrección.

\section{Fray Luis de Granada}

Fray Luis de Granada (1504-1588) publicó en 1554 el Libro de la oración y meditación, en el que expuso el método de oración mental, seguramente practicado en Escalaceli de Córdoba, donde estuvo de 1534 a $1545^{96}$. Estructura a lo largo de la obra varias semanas de oración, divididas en meditaciones matinales y vespertinas, las primeras dedicadas a la vida, pasión y muerte de Cristo y las segundas, al propio conocimiento como pecador y a la vanidad del mundo. Las meditaciones matinales de la segunda semana -capítulo X-están dedicadas a la pasión y muerte de Cristo.

La meditación consiste en aplicar «el entendimiento y la voluntad, para entender y gustar lo que se lee». Todas las meditaciones comienzan con la invitación a contemplar con los ojos exteriores («ve»y «mira») para focalizar la atención del alma en la escena que propone la lectura, mediante una descripción literaria totalmente realista y detallada. Fray Luis denomina a este momento desencadenante de la meditación la «licción». A partir de ella se pone en

\footnotetext{
${ }^{93}$ Ibid.

${ }^{94} \mathrm{Ibid}$., parte I, cap. 2, en Místicos franciscanos españoles, 43.

${ }^{95} \mathrm{Ibid}$., parte II, cap. 13, en Místicos franciscanos españoles, 200.

${ }^{96}$ Para las citas del Libro de la oración y meditación hemos usado la edición de J. J. de Mora, en Obras de Fray Luis de Granada II, Madrid 1848. Cf. también Fray Luis de Granada, Obras completas (52 vols.). Ed. A. Huerga et al. (Madrid, desde 1994). El éxito del Libro de la oración y meditación puso de relieve el grado de aceptación de la oración mental en la sociedad del siglo XVI. Se publicó en 1554 y, al año siguiente, ya tuvo una reedición. Tras ser incluido en el Índice de Valdés de 1559 , reapareció corregido en 1566 . Fue reimpreso nuevamente en 1573 y en 1579. Cf. A. Huerga. "Génesis y autenticidad del Libro de la oración y meditación», Revista de Archivos, Bibliotecas y Museos 59 (1953): 135-183; Id., «Fray Luis de Granada entre mística, alumbrados e Inquisición», Angelicum 66/4 (1988): 540-564; A. Llin Chafer, «Fray Luis de Granada y la democratización de la oración», Anales valentinos 34 (1991): 247-270; A. Rico Seco, «Fray Luis de Granada, maestro predilecto de Santa Teresa», Ciencia Tomista 113 (1986): 85-107.
} 
marcha el entendimiento o la imaginación; en el primer caso, se llama «meditación intelectual»y, en el segundo, «meditación imaginaria (...) de cosas que se pueden figurar con la imaginación, como son todos los pasos de la vida y pasión de Cristo» ${ }^{97}$. Con la imaginación, Fray Luis pretende introducir al lector en la escena mediante la representación "de la manera que ella es, o de la manera que pasaría, y hacer cuenta que allí, en aquel mesmo lugar donde estamos, pasa todo aquello en presencia nuestra; para que con esta representación de las cosas sea más viva la consideración y sentimiento dellas"98. Llega incluso esta representación mental realista y actual a trasmitir las sensaciones de Cristo al orante: "Y no pienses esto como cosa ya pasada, sino como presente; no como dolor ajeno, sino como tuyo propio. Y para ti mismo ponte en lugar del que padesce, y mira lo que sentirás si en parte tan sensible como es la cabeza, te hincasen muchas y muy agudas espinas que penetrasen hasta los huesos"

Tras la «licción», la meditación propiamente dicha consiste en «recogernos a considerar, rumiar y pensar, con toda la atención que pudiéramos, lo que hemos leído». Aquí se pasa del entendimiento a la voluntad, que es la parte fundamental del alma y obtiene así los «afectos» necesarios para crecer en virtud. Por eso, aconseja al lector que «procure tratar este negocio más con afectos y sentimientos de la voluntad que con discursos y especulaciones del entendimiento» ${ }^{100}$. Fray Luis cree que «la materia, pues, de la meditación son todas aquellas cosas cuya consideración nos puede mover a algún afecto devoto $(. ..){ }^{101}$; por eso, "la principal materia de la meditación es la sacratísima pasión del Salvador (...). Entre todas las devociones del mundo, no hay otra más segura, ni más provechosa, ni más universal para todo el género de personas que la memoria de la sagrada pasión"102. Y repite con frecuencia los seis puntos en que se debe ocupar la meditación para mover la voluntad: "la grandeza de sus dolores, la gravedad de nuestro pecado, la alteza del beneficio, la excelencia de la divina bondad, la muchedumbre de virtudes de Cristo que allí resplandecen, y la conveniencia de este medio que Dios tomó para nuestra redención" ${ }^{103}$. El fruto de estas consideraciones no son conclusiones teóricas, sino que «estas seis cosas hemos de considerar para seis efectos, en los cuales consiste todo el aprovechamiento de la vida espiritual». Estos sentimientos son: compasión de Cristo, dolor de los pecados, agradecimiento del beneficio,

\footnotetext{
${ }^{97}$ Libro de la oración y meditación, parte I, cap. 5, en Obras II, 13.

${ }^{98}$ Ibid.

${ }^{99} \mathrm{Ibid}$., parte I, cap. 10, en Obras II, 75, «meditación para el jueves por la mañana».

${ }^{100} \mathrm{Ibid}$., parte I, cap. 8, en Obras II, 16.

${ }^{101}$ Guía de pecadores, libro III, en Obras II, 276.

${ }^{102}$ Libro de la oración y meditación, parte I, cap. 11, en Obras II, 89.

${ }^{103} \mathrm{Ibid}$. En otras ocasiones lo formula en forma de pregunta.
} 
correspondencia de amor a Dios, deseo de imitar las virtudes de Cristo y admiración de la sabiduría divina ${ }^{104}$.

Finalmente, el orante, llegando al final del proceso, es invitado a un coloquio interior con Dios de acción de gracias, ofrecimiento personal y petición (u «oración») del amor de Dios con el que concluye la oración.

Fray Luis de Granada escribió Los seis libros de la Rhetorica ecclesiatica o de la manera de predicar ${ }^{105}$, en lo que describe la utilización por parte de los predicadores del arte oratoria «que en gran manera sirve para persuadir». La finalidad de la retórica no es entretener ni enseñar doctrina, sino convencer al lector: «Conviene pues que el predicador elocuente, cuando persuade alguna cosa que debe hacerse, no enseñe solo para instruir, no deleite solo para entretener, sino que convenza y doble para triunfar» ${ }^{106}$. Para hacer «al hombre bueno y virtuoso, que es el fin que la doctrina cristiana pretende» es necesario primero «ganarle la voluntad y persuadirle», afirma en el prólogo. Y, desde esta óptica, plantea su biografía de San Juan de Ávila, como el «perfecto predicador» ${ }^{107}$.

\section{San Pedro de Alcántara}

San Pedro de Alcántara (1499-1562) escribió el Tratado de oración y meditación entre 1541 y $1551^{108}$. Su obra parece una «recopilación» del Libro de la oración y meditación y del volumen segundo de Guía de pecadores de Fray Luis de Granada. Los franciscanos lo adoptaron durante mucho tiempo como manual de iniciación por lo que tuvo una gran difusión. El capítulo IV está dedicado a la meditación de la pasión que organiza en ritmo semanal, prácticamente con las mismas indicaciones de Fray Luis de Granada, salvo que

${ }^{104}$ Obras I, 272. En la Guía de pecadores presenta de nuevo resumidamente estos dos pasos de la lectio y la meditatio: «La manera de tratar cada uno de estos misterios es poniendo primero el texto del santo evangelio (que es la más alta y más dulce escritura de cuantas hay en el mundo) y después notando algunos puntos morales y devotos sobre que se pudiese fundar esta consideración: de los cuales unos sirven para la imitación de las virtudes de Cristo, otros para el agradecimiento de sus beneficios, otros para compasión de sus trabajos, otros para devoción y otros también para despertar el amor de este soberano Señor, y otros para otros efectos y virtudes semejantes, según que el Señor nos diere a entender» (Obras I, 313).

${ }^{105}$ En Obras XI/3 (Madrid, 1945), 488-642.

${ }^{106}$ Ibid., 559.

${ }^{107}$ Cf. J. Eguiluz Pacheco, «La prosa retórica de Fray Luis de Granada», en AISO. Actas II (1990) 315-321, cita 321.

${ }^{108}$ P. de Alcántara, Tratado de la oración y meditación, en R. Sanz Valdivieso (ed.), Místicos franciscanos españoles I. Vida y escritos de San Pedro de Alcántara (Madrid, 1996). Cf. también para un estudio más crítico y documentación la tesis doctoral del R. López Ruano, Edición crítica de El Tratado de la oración y meditación de san Pedro de Alcántara (tesis doctoral, Universidad de Extremadura; Cáceres, 2009). 
recomienda que la meditación de la pasión se haga en la oración vespertina y no en la matutina.

\section{San Ignacio de Loyola}

San Ignacio (1491-1556) publicó los Ejercicios espirituales en $1548^{109}$. No son un plan de oración para la vida de cada día, sino la programación de un mes para "preparar y disponer el alma, para quitar de sí todas las afecciones desordenadas, y después de quitadas para buscar y hallar la voluntad divina en la disposición de su vida para la salud del ánima""110.

La primera semana está dedicada al conocimiento de sí o a la consideración de los pecados, mientras que, las tres semanas restantes, los Ejercicios se centran en los «misterios de la vida de Cristo»: la segunda, en la encarnación y vida pública; la tercera, en la pasión; y la cuarta, en la resurrección y la ascensión. San Ignacio establece una gradación o progreso a lo largo del mes: la primera semana se corresponde con la vida purgativa y la segunda con la vida iluminativa ${ }^{111}$. El paso de una a otra no es para todos: están excluidos aquellos «de poco subiecto o de poca capacidad natural», que no pueden hacer «otros algunos exercicios, que están fuera de la primera semana» ${ }^{112}$. Con la tercera semana, dedicada a la pasión, «la contemplación ocupa todo el tiempo del ejercitante, la elección ya está hecha [en la segunda semana], no hay nuevas reglas de discernimiento y la actitud del ejercitante es más pasiva que en las dos semanas anteriores» ${ }^{113}$.

La estructura de un rato de oración del ejercitante según el método de San Ignacio tiene cuatro partes: comienza con la oración preparatoria, que consiste en «pedir gracia, a Dios nuestro Señor, para que todas mis intenciones, acciones y operaciones sean puramente ordenadas en servicio y alabanza de su divina majestad» ${ }^{114}$; después vienen los preámbulos o preludios que permiten al ejercitante situarse y recogerse utilizando la imaginación: «el primer preámbulo es, composición viendo el lugar» ${ }^{115}$, y unido a él «traer la historia

\footnotetext{
${ }^{109}$ Cf. Ejercicios espirituales (Bilbao, 1998) (citaremos el texto según esta edición indicando solo el número de parágrafo); J. Guevara, «Misterios de la vida de Cristo», en Diccionario de espiritualidad ignaciana II (Madrid, 2007); I. Iparraguirre, Práctica de los Ejercicios de San Ignacio de Loyola en la vida de su autor (1522-1556) (Roma, 1946), 31-32; M. Rotsaert, Ignace de Loyola et les Renouveax Spirituels en Castille au debut du XVI siècle (Roma, 1982), 43-81.

${ }^{110}$ Ejercicios Espirituales, núm. 1.

${ }^{111}$ Ibid., núm. 10.

${ }^{112}$ Ibid., núm. 18.

113 J. Guevara, «Misterios de la vida de Cristo», en Diccionario de espiritualidad ignaciana II, 1254.

${ }^{114}$ Ejercicios Espirituales, núm. 46.

${ }^{115}$ Ibid., núm. 47.
} 
de la cosa que tengo que contemplar» ${ }^{116}$, y a continuación «demandar a Dios nuestro Señor lo que quiero y deseo» ${ }^{117}$ alcanzar; en tercer lugar, los puntos de la oración, que consisten en aplicar los sentidos para «ver», «oír», «mirar lo que las personas hacen», pero no solo los sentidos corporales sino también los del alma que «siente (...) consolación o desolación»; y finalmente, la oración concluye con el coloquio que «se hace, propiamente, hablando, así como un amigo habla a otro» ${ }^{118}$.

Por lo que se refiere a la meditación de la pasión en la tercera semana, tras la oración preparatoria, los preámbulos «traen la historia», que correspondería a la «lectio» o memoria del pasaje que se va a meditar, y recogen la intención de la meditación, que, en este caso, es sentir «dolor, sentimiento y confusión porque por mis pecados va el Señor a la pasión» ${ }^{119}$ o bien «dolor con Cristo doloroso, quebranto con Cristo quebrantado, lágrimas, pena intensa de tanta pena que Cristo pasó por mí» ${ }^{120}$. En cuanto a los puntos de oración, después de aplicar los sentidos corporales, pide al ejercitante, en primer lugar, contemplar el sufrimiento voluntario de Cristo («considerar lo que Cristo nuestro Señor padece en la humanidad o quiere padecer, según el paso que se contempla» ${ }^{121}$ ); en segundo lugar, la voluntad de Dios en este sufrimiento («considerar, cómo la divinidad se esconde (...) y cómo deja padecer la sacratísima humanidad tan crudelísimamente» ${ }^{122}$ ), y finalmente, cómo debe determinarse la voluntad del hombre («considerar, cómo todo esto padece por mis pecados, etc., y qué debo yo hacer y padecer por él» ${ }^{123}$ ).

\subsection{Visión de conjunto}

Tras haber presentado aquellos autores de la primera mitad del siglo XVI que, en el entorno de San Juan de Ávila, proponen la meditación de la pasión en ritmo semanal, y teniendo como punto de referencia a nuestro autor, recogemos algunos aspectos que nos ayuden a distinguir un método y un género devocional común.

En primer lugar, todos estos autores comparten una concentración soteriológica en la pasión del Señor. Esta importancia histórico-salvífica de la pasión

\footnotetext{
${ }^{116}$ Ibid., núm. 102.

${ }^{117}$ Ibid., núm. 48.

${ }^{118}$ Ibid., núm. 54.

${ }^{119}$ Ibid., núm. 193.

${ }^{120}$ Ibid., núm. 203.

${ }^{121}$ Ibid., núm. 195.

${ }^{122}$ Ibid., núm. 196.

${ }^{123}$ Ibid., núm. 197.
} 
se refleja en el creciente peso que su meditación tiene en la oración creyente. Para ellos, centrarse en la meditación de la pasión no quiere decir rechazar los demás temas de oración, sino acudir al «fontal», desde el que adquiere luz todo lo demás, incluso la entera vida de Cristo. En la tradición monástica ${ }^{124}$ y franciscana del siglo XIII y XIV, la meditación de la pasión era el tema más adecuado para los «principiantes» y estaba orientado preferentemente al abandono de los vicios y al crecimiento en virtud. Sin embargo, bajo la influencia de la devotio moderna, y en la organización de la oración metódica, la meditación de la pasión se va asignando cada vez más a los «perfectos». En Francisco de Osuna todavía forma parte de la entrada en la oración. En Bernardino de Laredo es ya un estadio sucesivo, cercano a la contemplación. En San Ignacio de Loyola se sitúa en la vía unitiva y recibe el nombre de contemplación ${ }^{125}$.

Además, en todos ellos, la meditación de la pasión consiste en un ejercicio de interiorización que busca la participación personal en la pasión para recibir su efecto salvífico. Si mediante la vis sacramenti se hace real y efectiva la gracia de pasión, mediante la vis meditationis se hace presente y eficaz por el mismo modo en que se realizó. El efecto objetivo de salvación hubiera sido igual si Jesús hubiera realizado la salvación de otra manera, pero este modo de hacerlo tiene como finalidad llegar a «tocar» subjetivamente los «afectos» del hombre. Para lograr esa participación personal es necesario poner en juego las potencias del alma: la memoria, la inteligencia y la voluntad. En el ejercicio de la meditación, la memoria representa la materia a tratar; la inteligencia profundiza en el tema; y la voluntad alcanza pasivamente la comunicación del amor de Dios. Como se trata de un ejercicio purificador del alma, que reconstruye en ella la imagen de Dios, en todos estos autores se aprecia una creciente interrelación de la meditación de la pasión con el ejercicio del propio conocimiento o aniquilación.

También se percibe una cierta evolución en el concepto de contemplación. De una visión monástica que entiende la contemplación como éxtasis, como salida de sí y participación en la gloria de Dios, hemos pasado a una comprensión de la contemplación como interiorización, recogimiento. Si la meta de la contemplación monástica era subir a la altura de los cielos, donde Dios reina glorioso, ahora el objetivo es entrar en lo más hondo del corazón humano, donde Dios se encuentra con el hombre. Por otra parte, en esta meditación

${ }^{124}$ Todavía en el siglo XVII encontramos afirmaciones sobre el uso de la pasión para los principiantes. En la «Introducción de novicios cistercienses de la Congregación de San Bernardo y observancia de Castilla» (1635), de Froilán de Urosa, se recomienda al Maestro de novicios que «procure aficionar a los novicios a meditar en la pasión de Cristo».

${ }^{125}$ G. Lercaro, Metodi di orazione mentale (Milán, 1957), 180 explica cómo la meditación de la pasión en el desarrollo de la oración mental no es ya para los incipientes sino el camino del cristiano hacia la perfección y hacia Dios; deja de ser punto de partida de la oración para convertirse en punto de llegada. 
interior, la memoria vitae et passionis Christi provoca no solo un effectus mentis, sino también effectus operis en la imitatio Christi, de modo que la culminación de la meditación no es ya la admiración sino la acción, la imitación.

Sería interesante profundizar más en las similitudes y diferencias en puntos concretos, como el lugar y tiempo adecuado para la oración de recogimiento, su ambiente físico, las posturas corporales, el puesto de la oración vocal y de la lectura de la escena, la descripción de los «ejercicios espirituales» de meditación, el valor que conceden a los «sentidos externos», los olores, las representaciones vivas que conmueven el espíritu del hombre... Sin embargo, nos concentraremos en analizar lo más común e identificativo de todos ellos: la distribución de la meditación de la pasión a lo largo de la semana y la composición literaria y devota que hacen para cada una de las escenas, el «paso» como género literario común.

\subsubsection{La estructura semanal de la meditación de la pasión}

Estos autores no solo comparten convicciones comunes, sino en gran medida una misma metodización: la alternancia de las meditaciones según el ritmo semanal en lugar del diario seguido en los monasterios medievales, prescindiendo, por tanto, de la referencia a las horas litúrgicas ${ }^{126}$. Este cambio indica una nueva organización del «tiempo», distinta al ritmo del horologium del officium. El orante no vive ya una jornada jalonada por el coro, sino que encuentra los momentos más adecuados para la oración en el principio y fin del día, de modo que pueda conjugarlos con su vida en el mundo.

Esta organización hebdomadaria remite a la celebración de la semana santa, de la que tenemos testimonios antiguos en la liturgia de Tierra Santa ${ }^{127}$, previa incluso al monacato. En San Juan de Ávila, las referencias a la «Semana mayor» son explícitas para justificar la distribución semanal de la meditación de la pasión: "En otro tiempo había sentimiento de la pasión de Jesucristo; en la premitiva Iglesia duraba la misa y el oficio hasta la mañana que Jesucristo resucitó. Ya no hay nada de esto, sino, en pasando el viernes, ¡alyo!, ya es pas-

\footnotetext{
${ }^{126}$ Todavía quedan reminiscencias en todos ellos. Ya hemos anotado en el texto la propuesta diaria de Bernardino de Laredo. También San Ignacio propone una lectura diaria según se adapte al tipo de vida de cada uno. Cf. Ejercicios espirituales, 209: «Tome a media noche la cena; a la mañana el huerto...» y así continúa por el resto de las horas del día.

${ }^{127}$ El Itinerarium Egeriae, 30, 1 habla de la «septimana paschalis» o «septimana maior» que recuerda la última cena y la oración en el Huerto el jueves, la muerte en cruz el viernes, la vigilia pascual el sábado y el domingo la resurrección, días a los que se juntó muy pronto el domingo de Ramos para cerrar toda la semana. Posteriormente se añaden en la tradición la referencia a la traición de Judas el miércoles. Cf. J. A. Jungmann, «Il ciclo liturgico settimanale», en id., Eredità liturgica e attualità pastorale (Roma, 1962), 386-424.
} 
cua"128. Y para celebrar «con dolor esta dolorosa memoria», dice el Maestro Ávila, "señaló la Iglesia el tiempo de la Semana Santa, en la cual las cruces se visten de luto y mudan los altares sus ornamentos, cántase la pasión del Señor cuatro veces, según los cuatro evangelistas que la escribieron, y hácese de ella sermón, y todo provoca a sentimiento de compasión y tristeza, para que así paguemos el servicio de devoción al Señor que padeció por nosotros" ${ }^{129}$. Lo mismo que añora para los días santos lo extiende luego al resto del año: "Tenga vuestro corazón sentimiento todos los días de vuestra vida, el jueves y viernes hasta la tarde, de pasión de Jesucristo; y desde el viernes en la tarde y el sábado, de los dolores de la Virgen María. No se os olvide, en viniendo el sábado, de tener memoria particularísima, sin que falte día, de los dolores que la Virgen María pasó" 130.

Fue la devotio moderna la que introdujo esta novedad del ciclo semanal en la meditación de la pasión, para lo cual comenzó a hacer algunas composiciones literarias llamadas «membra», o misterios de la vida de Cristo. San Juan de Ávila también hace una distribución semanal de la pasión dividiéndola en «pasos», para «tener algún orden... porque no ande vagueando cuando el ánima no se inclina a alguno particular» ${ }^{131}$, aunque para la «lectura» concreta de estos «pasos» (o «membra») remite a algunos libros devotos, como ya hemos indicado: las Meditationes, la Passio duorum, la Vita Christi no estaban divididos en escenas por los días de la semana, y otros, en cambio, como Francisco de Osuna o Fray Luis de Granada, tienen ya una distribución semanal, si bien ligeramente diversa a la que nuestro autor propone.

Las dos distribuciones semanales de la pasión más representativas del Maestro Ávila están en la Carta 5 y el tratado sobre la oración del Audi Filia. Comparándolas en un cuadro sinóptico con la distribución que hacen los otros autores del recogimiento español, podemos ya sacar algunas conclusiones y particularidades.

En la tabla adjunta hemos intentado colocar cronológicamente a los autores del recogimiento para detectar no solo las diferencias, sino también para sugerir una posible evolución entre ellos. La distribución de la semana en Francisco de Osuna, tomada de la Segunda parte del Abecedario espiritual ${ }^{132}$,

\footnotetext{
${ }^{128}$ Ser 67, 3, en Obras III, 895.

${ }^{129}$ Ser 37, 22, en Obras III, 497. Esta es ya una influencia de la devotio moderna en la que ya «aparece la semana como una reminiscencia de la Semana Santa» (J. A. Jungmann, «Il ciclo liturgico settimanale», 388).

${ }^{130}$ Ser 67, 17, en Obras III, 902.

${ }^{131}$ Carta 236, en Obras IV, 752ss.

${ }^{132}$ Ya hemos señalado que el tema de la pasión lo trata también en otras obras. Aquí hemos tomado la distribución que extracta M. Andrés Martín, «En torno a la 'theologia crucis' en la espiritualidad española (1450-1559)», Diálogo ecuménico 6 (1971): 370.
} 
sigue el Rosetum exercitiorum spiritualium et sacrarum meditationum de Mombaer que se centra en siete prerrogativas de Cristo en lugar de individuar pasajes de la pasión, y en este sentido es la más antigua ${ }^{133}$.

Bernardino de Laredo ${ }^{134}$ es el primer autor del recogimiento español que distribuye el relato continuo de la pasión en los días de la semana. Tiene una cierta influencia de las Meditationes vitae Christi, que, como él, comienza la narración de la pasión después de la última cena, y en este sentido está más cercano a la tradición monástica, ya que la eucaristía no entraba a formar parte de las Horas canónicas que representaban la pasión.

Como Bernardino, tampoco San Juan de Ávila prevé la meditación de la última cena en la distribución semanal de las escenas de la pasión de las Cartas 5 y 236; en cambio, en el Audi Filia la coloca el jueves, con lo que el viernes recoge los pasos asignados en las Cartas 5 y 236 al jueves. De esta forma podemos conjeturar que la propuesta de las Cartas podría ser anterior a la del Audi Filia ${ }^{135}$. Y, además de la introducción de una nueva escena, hemos de destacar en nuestro autor su interés manifiesto por respetar el carácter litúrgico «propio» de cada día de la semana a pesar de tener que romper la secuencia temporal del relato: «el jueves, no le podemos quitar su misterio muy excelente»; y el sábado: «tened memoria de pensar en este día las grandes angustias que la Virgen y Madre pasó»; y el domingo «es diputado al pensamiento de la resurrección» ${ }^{136}$. Probablemente esto se debe a su idea de reproducir el misterio de la muerte y resurrección de Cristo en cada semana del año y no solamente una vez en la Semana Santa ${ }^{137}$, como hemos indicado.

${ }^{133}$ Alonso de Orozco incluso hace una distribución según las horas del día, más ajuntada aún a la piedad monástica, cf. Memorial de Amor santo, 415-425. También en San Juan de Ávila quedan algunos vestigios de esta forma de considerar la pasión, cf. Dialogus, 15 en Obras II, 778 donde recomendando la meditación de la pasión dice: «Poned vuestro corazón delante del Señor Jesús crucificado, que es vuestro Señor, y Juez, y Padre».

${ }^{134}$ Cf. también M. Andrés, La Teología española en el siglo XVI II (Madrid, 1977), 214-218.

${ }^{135}$ Esta novedad probablemente es fruto de la influencia de la Vita Jesu Christi de Ludolfo de Sajonia en San Juan de Ávila, pues comienza su relato de la pasión con la última cena en los cap. 51-67. De él seguramente pasó a los manuales de oración mental que surgieron en los monasterios como el Compendio breve de ejercicios espirituales, 324-400; 415-463.

${ }^{136} \mathrm{AF}$ (2) 72, 3, en Obras I, 692. Cf. M. Brunsó, «El espíritu litúrgico del P. Maestro Juan de Ávila», en Semana Avilista. IV Centenario de la muerte del Beato Maestro Juan de Ávila (Madrid, 1969), 169-197; J. Calveras, «La devoción al Corazón de María en el Beato Ávila», Manresa 18 (1946): 3-29; 221-256.

137 «Y para cumplir con esta obligación tan justa y celebrar con dolor esta dolorosa memoria». Para «esta primera consideración mirando la pasión en sí misma, que fue causadora de penas al Señor, y a nosotros de compasión», que ahora él propone semanalmente «señaló la Iglesia el tiempo de la Semana Santa, en la cual las cruces se visten de luto y mudan los altares sus ornamentos, cántase la pasión del Señor cuatro veces, según los cuatro evangelistas que la escribieron, y hácese de ella sermón, y todo provoca a sentimiento de compasión y tristeza, para que así paguemos el servicio de devoción al Señor que padeció por nosotros» (Ser 37, 22, en Obras III, 497). Esta es ya una influencia 


\begin{tabular}{|c|c|c|c|c|c|c|c|}
\hline$D / A$ & Osuna & Bernardino L. & $\begin{array}{l}\text { San Juan de } \\
\text { Ávila (5) }\end{array}$ & $\begin{array}{c}\text { San Juan de Ávila } \\
(A F)\end{array}$ & $\begin{array}{l}\text { Fray Luis de } \\
\text { Granada }\end{array}$ & $\begin{array}{l}\text { San Pedro de } \\
\text { Alcántara }\end{array}$ & $\begin{array}{c}\text { San Ignacio de } \\
\text { Loyola }\end{array}$ \\
\hline Lunes & Juez & $\begin{array}{l}\text { De Getsemaní } \\
\text { a Caifás }\end{array}$ & $\begin{array}{l}\text { Ida al Huerto, } \\
\text { oración y } \\
\text { prendimiento }\end{array}$ & $\begin{array}{l}\text { La oración } \\
\text { en el Huerto, } \\
\text { prendimiento y } \\
\text { proceso religioso }\end{array}$ & $\begin{array}{l}\text { Última cena y } \\
\text { lavatorio de los } \\
\text { pies }\end{array}$ & $\begin{array}{l}\text { Lavatorio e } \\
\text { institución de la } \\
\text { eucaristía }\end{array}$ & $\begin{array}{l}\text {-Desde Betania a } \\
\text { Jerusalén (Última } \\
\text { Cena) } \\
\text {-De Jerusalén al } \\
\text { Huerto }\end{array}$ \\
\hline Mart. & Médico & $\begin{array}{l}\text { De Caifás a la } \\
\text { columna }\end{array}$ & $\begin{array}{l}\text { Desde allí hasta } \\
\text { la columna } \\
\text { inclusive }\end{array}$ & $\begin{array}{l}\text { Proceso civil y } \\
\text { flagelación }\end{array}$ & $\begin{array}{l}\text { La oración en } \\
\text { el Huerto y el } \\
\text { prendimiento }\end{array}$ & $\begin{array}{l}\text { La oración en el } \\
\text { Huerto, prendi- } \\
\text { miento y ante Anás }\end{array}$ & $\begin{array}{l}\text {-Del Huerto a Anás } \\
\text {-De Anás a Caifás }\end{array}$ \\
\hline Miér. & Deudor & $\begin{array}{l}\text { De la columna } \\
\text { al Ecce Homo }\end{array}$ & $\begin{array}{l}\text { La coronación } \\
\text { y el Ecce } \\
\text { Homo }\end{array}$ & Ecce homo & $\begin{array}{l}\text { Proceso } \\
\text { religioso y } \\
\text { proceso civil }\end{array}$ & $\begin{array}{l}\text { Proceso antes Cai- } \\
\text { fás, negaciones de } \\
\text { Pedro y flagelación }\end{array}$ & $\begin{array}{l}\text {-De Caifás a Pilato } \\
\text {-De Pilato a } \\
\text { Herodes }\end{array}$ \\
\hline Juev. & Pastor & $\begin{array}{l}\text { Del Ecce Homo } \\
\text { a la caída con la } \\
\text { cruz }\end{array}$ & $\begin{array}{l}\text { La sentencia y } \\
\text { el camino de la } \\
\text { cruz }\end{array}$ & $\begin{array}{l}\text { Última cena y la- } \\
\text { vatorio de los pies }\end{array}$ & $\begin{array}{l}\text { Ecce Homo y } \\
\text { via crucis }\end{array}$ & $\begin{array}{l}\text { Coronación de } \\
\text { espinas, Ecce Homo } \\
\text { y vía crucis. }\end{array}$ & $\begin{array}{l}\text {-De Herodes a } \\
\text { Pilato } \\
\text {-Pilato Ecce Homo }\end{array}$ \\
\hline Vier. & Rey & $\begin{array}{l}\text { De la caída a la } \\
\text { enclavación }\end{array}$ & $\begin{array}{l}\text { La crucifixión } \\
\text { y muerte }\end{array}$ & $\begin{array}{l}\text { Condena, vía } \\
\text { crucis, crucifixión } \\
\text { y muerte }\end{array}$ & $\begin{array}{l}\text { Crucifixión y } \\
\text { muerte }\end{array}$ & $\begin{array}{l}\text { Crucifixión y } \\
\text { palabras de Cristo } \\
\text { en la cruz }\end{array}$ & $\begin{array}{l}\text {-De Pilato a la cruz } \\
\text {-La muerte en cruz }\end{array}$ \\
\hline Sába. & Esposo & $\begin{array}{l}\text { De la cruz al } \\
\text { monumento }\end{array}$ & $\begin{array}{l}\text { La disposición } \\
\text { de la cruz y } \\
\text { sepultura. }\end{array}$ & $\begin{array}{l}\text { Lanzada, } \\
\text { descendimiento, } \\
\text { piedad, sepultura y } \\
\text { descenso al limbo } \\
\text { e ida al paraíso }\end{array}$ & $\begin{array}{l}\text { Descendimien- } \\
\text { to y sepultura }\end{array}$ & $\begin{array}{l}\text { Lanzada, } \\
\text { descendimiento y } \\
\text { sepultura }\end{array}$ & $\begin{array}{l}\text {-De la cruz al } \\
\text { monumento } \\
\text {-Del monumento a } \\
\text { la casa de María }\end{array}$ \\
\hline Dom. & Padre & $\begin{array}{l}\text { Del } \\
\text { monumento a } \\
\text { la resurrección }\end{array}$ & $\begin{array}{l}\text { La } \\
\text { Resurrección y } \\
\text { gloria }\end{array}$ & $\begin{array}{l}\text { Resurrección y } \\
\text { gloria }\end{array}$ & $\begin{array}{l}\text { Aparición } \\
\text { a María } \\
\text { Magdalena y a } \\
\text { los Doce }\end{array}$ & $\begin{array}{l}\text { Descenso al limbo, } \\
\text { resurrección, apa- } \\
\text { rición a la Virgen, } \\
\text { a la Magdalena, a } \\
\text { los discípulos, y } \\
\text { ascensión }\end{array}$ & $\begin{array}{l}\text {-Muerte: apartado } \\
\text { cuerpo y alma. } \\
\text {-Soledad de María } \\
\text {-Contemplación } \\
\text { general de toda la } \\
\text { pasión. }\end{array}$ \\
\hline
\end{tabular}


Fray Luis de Granada y San Pedro de Alcántara coinciden lógicamente en la distribución de la semana. Incorporan ya la institución de la eucaristía como San Juan de Ávila, pero no el jueves sino el lunes, primando en ellos el criterio cronológico sobre el «litúrgico-sacramental», y acentúan aún más la presencia de la Virgen María en la meditación de la pasión con inclusión de la meditación de la aparición a María, que no recogen los Evangelios. Por otra parte, pasan el Ecce Homo al jueves, cuando en Bernardino de Laredo y en el primer San Juan de Ávila, estaba el miércoles, dándole así mayor relieve en lugar de -como hubiera sido más lógico- distribuir la acumulación de escenas del viernes, que había recogido los pasos del jueves, cuando este día se dedicó a la eucaristía. Esta acumulación mantenida por Fray Luis de Granada, a pesar no asignar ya la última cena al jueves, indica que trabaja con el esquema de San Juan de Ávila.

San Ignacio de Loyola ${ }^{138}$ señala dos meditaciones de la pasión para cada día de la tercera semana de los Ejercicios. Sigue el ritmo de los anteriores, únicamente que, al dedicar a la resurrección toda la cuarta semana, el domingo amplía aún más la meditación mariana. La mayor aportación de San Ignacio es la introducción de una meditación sobre toda la pasión en conjunto, algo en lo que insiste con frecuencia.

Además del ritmo semanal, tenemos que dejar constancia de que todas las escenas están centradas en Cristo: cada una describe algo que Cristo hace o padece. Como ya sucedía en la piedad medieval, Cristo es siempre protagonista y centro de la acción. Fuera de la atención reservada a María, no hay ninguna escena que se centre en otro personaje, como pudiera ser la negación de Pedro, la traición de Judas o la Verónica, el Cirineo... que se encuentran en otras prácticas de piedad ${ }^{139}$. Esto se debe entender como un subrayado cristocéntrico, más que como una reserva hacia la piedad popular. De hecho, algunas escenas provienen más de la devoción popular que del propio texto evangélico; escenas tan importantes como la flagelación o la coronación de espinas muestran esta influencia al destacar un hecho tan puntual en los evangelios. Además, estos autores no remiten a la lectura directa del texto bíblico, sino que recrean la Escritura en una composición literaria que sirve de base al orante para iniciar su meditación personal.

de la devotio moderna en la que ya «aparece la semana como una reminiscencia de la Semana Santa» (J. A. Jungmann, «Il ciclo liturgico settimanale», 388).

${ }^{138}$ Ejercicios espirituales, núm. 190-217. Cf. J. Guevara, «Misterios de la vida de Cristo», en Diccionario de espiritualidad ignaciana II, 1254.

${ }^{139}$ Llama la atención cómo en la piedad del recogimiento no se utilizan escenas que hubieran podido dar mucho juego al afecto y que, sin embargo, aparecen en otras prácticas de piedad, como el viacrucis o el rosario, cuya formulación definitiva en «misterios» o «estaciones» datan de la misma fecha. Cf. U. Köpf, «Passionsfrömmigkeit», 726 
Otra característica de las escenas de la pasión para cada día es que todas ellas se diferencian por el lugar en que se desarrollan, de manera que el cambio de escenario y de los personajes que en él actúan, conlleva cambio de escena para cada día. Este dato remite, sin duda, a la representabilidad de cada escena, tanto en un relato literario como en un grupo escultórico. La importancia del lugar se refleja ya en la misma forma de dividir las escenas con las preposiciones «desde»y «hasta», indicando que se refieren a lo que sucedió desde que llegó a un lugar hasta que marchó a otro. Muy probablemente esto se debe a la influencia de la Vita Jesu Christi de Ludolfo de Sajonia en los autores del recogimiento español, pues ya él divide los capítulos de su libro sin indicación temática sino espacio-temporal mediante estas mismas preposiciones $^{140}$. Estas precisiones geográficas y temporales ayudan al tipo de meditación que usa la composición de lugar para introducir al orante en las circunstancias de la escena, «pareciéndole que es aquel el mesmo lugar donde lo padecía» ${ }^{141}$.

\subsubsection{El género literario «paso»}

Ninguno de estos autores está movido por criterios estéticos. Su objetivo es religioso, no literario. Más que el contenido, conocido de sobra por el lector, están interesados en trasmitir y compartir la propia experiencia espiritual y persuadir al lector con todo tipo de recursos.

San Juan de Ávila utiliza la palabra «paso» ${ }^{142}$ para referirse a cada una

\footnotetext{
${ }^{140}$ Cf. Ludolfo de Sajonia, La vida de Cristo (Madrid, 2010), en los capítulos correspondientes a la pasión.

${ }^{141}$ Carta 236, en Obras IV, 754.

${ }^{142}$ Mucho menos frecuente es el uso de la palabra «misterio» para referirse a las escenas de la pasión. Cf. por ejemplo, Dialogus, 20, en Obras II, 782; Plática 4, 5, en Obras I, 828: «los misterios de su vida y pasión». Sin embargo, Francisco de Osuna, San Ignacio y Fray Luis de Granada usan más la expresión «misterio» que asimila la pasión con los otros temas de meditación en cuanto «misterios» contenidos en el símbolo de la fe. Cf. Fray Luis de Granada, Libro de la oración y meditación, cap. II: «Y aunque sea verdad que todas las cosas criadas y todas las Escripturas sagradas nos muevan a esto, pero generalmente hablando, los misterios de nuestra fe (que se contienen en el Símbolo, que es el Credo) son los más eficaces y provechosos para esto. Porque en él se trata de los beneficios divinos, del Juicio final, de las penas del Infierno y de la gloria del Paraíso, que son grandísimos estímulos para mover nuestro corazón al amor y temor de Dios; y en él también se trata la vida y pasión de Cristo nuestro Salvador, en la cual consiste todo nuestro bien. Sin embargo, la palabra «paso» también se extendió. Fray Luis de Granada la usa con frecuencia y luego la encontramos entre los jesuitas y la misma Santa Teresa. Cf. Libro de la Vida, capítulo 13, que propone a continuación un ejemplo práctico, «un paso de la Pasión» como «el modo de oración en que han de comenzar, y demediar y acabar todos, y muy excelente y seguro camino hasta que el Señor los lleve a otras cosas sobrenaturales» (Vida, 13, 12). Ella misma refiere de San Francisco de Borja: «Pues después que me hubo oído, díjome que era espíritu de Dios y que le parecía que no era bien ya resistirle más, que hasta entonces estaba bien hecho, sino que siempre comenzase la oración en un paso de la Pasión, y que si
} 
de estas escenas en que divide la pasión. Con este mismo sentido entró en el «Diccionario de la Real Academia Española» que en su acepción núm. 21 dice que «paso» es «cada uno de los sucesos más notables de la Pasión de Jesucristo» ${ }^{143}$. La acepción núm. 23 añade otro elemento, el literario: «paso» es una «cláusula o pasaje de un libro o escrito». Y la acepción 22 añade un elemento más, el figurativo: «paso» es la «efigie o grupo que representa un suceso de la Pasión de Cristo, y se saca en procesión por la Semana Santa». Sería muy interesante estudiar diacrónicamente cómo la palabra «paso» fue adquiriendo todos estos matices escriturísticos, literarios e iconográficos, y la importancia que la devoción de la «pasión» tuvo en esta evolución ${ }^{144}$.

En primer lugar, para nuestro autor «paso» es acontecimiento de la pasión. Hay una relación literal, directa y buscada, de «paso» con «pasión», de manera que muchas veces hace como un juego de palabras. Los «pasos» se refieren a los sufrimientos de Cristo en la pasión cuando dice: «Repartid los pasos de la pasión por los días de la semana», y explica que en cada paso hay que pensar en «lo que pasó» ${ }^{145}$. El contenido de cada paso es un sufrimiento, por eso puede decir aplicándolo a otros contextos: «Haced cuenta que estáis ya en el paso de vuestra muerte» ${ }^{146}$, donde «paso» es sinónimo de «trance».

$\mathrm{El}$ «paso» es, por tanto, un hecho algo que sucede, que pasa («cómo acaeció aquel paso») y que se puede describir («todo lo que el libro dijere cerca de aquel paso»). El Ecce homo, por ejemplo, es el «paso que había de pasar y traspasar a lo más dentro de nuestras ánimas» ${ }^{147}$. Es decir, es el sufrimiento de Cristo que se comunica como experiencia de dolor al alma orante. Pensar un «paso» concreto de la pasión consiste en «pensar lo que Jesucristo bendito pasó por amor» ${ }^{148}$. Y en este sentido, por extensión, también otros aconteci-

después el Señor me llevase el espíritu, que no lo resistiese, sino que dejase llevarle a Su Majestad, no lo procurando yo».

${ }^{143}$ Se ha estudiado la huella de San Juan de Ávila en el Diccionario de la Real Academia de la lengua española: M. A. Moreno Moreno, «El Maestro Juan de Ávila, autor de 'buen juicio, claridad y proporción': Autoridad de la RAE (1726-1770)», en M. ${ }^{a}$ D. Rincón González-R. Manchón Gómez (eds.), El Maestro Juan de Ávila (1500?-1569). Un exponente del humanismo reformista (Madrid, 2014), 357s; M. Quirós García-J. L. Ramírez Luengo, «Hacia una caracterización filológica de los escritos de Juan de Ávila», en ibid., 379-416; E. McClure Torrance, E., Style, Themes and Ideas in the Works of S. Juan de Ávila (Tesis Doctoral, New York University; New York, 1985), quien defiende que muchas de las cosas que dijo San Juan de Ávila y cómo las dijo son lenguaje actual.

${ }^{144}$ Cf. La presentación de la evolución en la Tesis Doctoral de I. Mira Ortiz, Semana santa y textos literarios de la pasión en la región de Murcia (Murcia, 2006), 61ss.

${ }^{145}$ AF (1) II, 47, en Obras I, 460.

${ }^{146}$ AF (1) II, 22, en Obras I, 446.

${ }^{147}$ AF (1) VI, 22, en Obras I, 523.

${ }^{148}$ Ser 23, 14, en Obras III, 283. 
mientos de la vida pública de Cristo se pueden llamar «paso», sin que tengan relación directa con la «pasión» ${ }^{149}$.

En segundo lugar, un «paso» es también el relato que narra el hecho acaecido. Cada una de las meditaciones se centra en una escena de la pasión relatada por los libros de devoción a los que remite San Juan de Ávila. También estos relatos son $«$ pasos» ${ }^{150}$.

$\mathrm{Y}$, en tercer lugar, «paso» se puede referir también a la imagen que lo representa, de manera que pensar un paso a veces consiste en mirar a su representación plástica: «Y poned dentro de vuestro corazón la imagen de aquel paso que quisiéredes pensar» ${ }^{151}$. Por eso puede recomendar: «tener algunas imágenes de los pasos de la pasión» ${ }^{152}$. Y así pueden aparecer los «pasos» en relación con las «procesiones» ${ }^{153}$.

Hechas estas precisiones terminológicas, tenemos que referirnos al estudio realizado por Armando Pego Puigbó sobre el «paso» como género literario en la literatura espiritual española del siglo XVI ${ }^{154}$, a partir de los presupuestos de la retórica moderna ${ }^{155}$. A. Pego no se ocupa del «paso» como un acontecimiento de la pasión de Cristo, sino más bien como el texto que lo narra: la «exposición y comentario de una breve escena de la pasión de Cristo, según los detalles del relato evangélico» ${ }^{156}$. Y para caracterizar este «género literario» compara la prosa literaria de Francisco de Osuna, Fray Luis de Granada y San Juan de Ávila en la descripción de la escena del Ecce Homo, constatando

${ }^{149}$ Cf. Carta 236, en Obras IV, 754, también aplica paso fuera de la pasión: «devoción en el nacimiento de Cristo, lo dejase por pensar en otro paso».

${ }^{150}$ Aunque no se refiere directamente a un texto de la Escritura, en algunas ocasiones «paso» también es sinónimo de «pasaje». Cf. Ser 33, 16, en Obras III, 413: «¿Y cómo sabré que tal paso de la Escritura quiere decir esto y esto...?»; Ser 48, 20, en Obras III, 609: «Mas el concilio Tridentino dice que aquel paso se entiende de la comida sacramentalmente hecha».

${ }^{151}$ AF (1) II, 49, en Obras I, 461.

${ }^{152}$ AF (1) II, 50, en Obras I, 462.

${ }^{153}$ Ser 37, 4-12, en Obras III, 490-493. En este sermón de víspera del Corpus, al que ya hemos hecho referencia, compara la procesión con los «pasos» de Cristo durante su pasión y reporta inclusos «pasos» físicos que tuvo que caminar para desplazarse de un lugar a otro.

${ }^{154}$ A. Pego Puigbó, «Un ejemplo de constitución genérica en la literatura espiritual: el 'paso' del Ecce Homo», Revista de Literatura 126 (2001): 369-400, trabajo realizado gracias a una beca postdoctoral del Ministerio de Educación y Ciencia en The Warburg Institute (Londres). Posteriormente ha incluido este artículo como un capítulo en su libro El renacimiento espiritual. Introducción literaria a los tratados de oración españoles (1520-1566), publicado por el Consejo Superior de Investigaciones Científicas en 2004.

${ }^{155}$ En concreto de G. Genette-A. Flower, Kinds of Literature. An Introduction to the Theory of Genres and Modes (Oxford, 1982), al que sigue en las p. 54-74, que presentan los acontecimientos de la pasión como topos (o motivo) para un relato literario.

${ }^{156}$ En la literatura del siglo de oro español «paso» designa un subgénero de teatro breve, en que destacó en el siglo XVI Lope de Rueda. Lógicamente este sentido no es el que desarrolla A. Pego Puigbó, sino que él intenta caracterizar otro género de carácter religioso al que da el mismo nombre. 
que en ninguno de ellos prima el elemento literario, sino que la finalidad espiritual de ayudar al lector en su meditación personal ${ }^{157}$, con lo cual la estructura y las figuras literarias utilizadas no dependen de criterios estilísticos sino pragmáticos. Por eso, encuentra dificultad para definir y clasificar el género en la historia de la literatura. Literariamente se trata de una «amplificatio»o «sermocinatio» ${ }^{158}$, que no se reduce a glosar los textos evangélicos, pues no se interesa tanto por la narración, sobradamente conocida por el lector, cuanto por el efecto que pretende producir en él. El paso es una actualización del evangelio con elementos tomados de la catequesis, la predicación, la apología, el comentario bíblico... para posibilitar que se haga experiencia de él ${ }^{159}$. En concreto, dice que Francisco de Osuna hace uso del exemplum, mientras que Fray Luis de Granada utiliza recursos tomados de meditación oracional, y San Juan de Ávila se caracteriza por convertir la meditación en una predicación. Ante la heterogeneidad de elementos literarios que incluye, A. Pego concluye que "el género 'paso' no representa, en definitiva, tanto el resultado de un conjunto de propiedades discursivas, formales y temáticas, cuanto el cauce que facilita la expresión de una experiencia humana y la posibilidad de su correcta interpretación".

De hecho, todas las figuras retóricas utilizadas -paralelismos, repeticiones o reduplicaciones semánticas, pathos, apostrofes retóricos...- pretenden incluir al lector en la escena, para lo cual Cristo o algún personaje de la escena establecen un diálogo con él, o buscan encarecer en el lector algún sentimiento o atraer su atención apostrofándolo en segunda persona. El objetivo retórico es «convencer», «persuadir» al oyente o al lector para que se «determine» a la perfección y a la unión con Dios. En la edad moderna la retórica de la argumentación y de las citas para demostrar una verdad es sustituida por la retórica de la metáfora y la imagen para seducir el espíritu a través de los sentidos ${ }^{160}$.

${ }^{157}$ La definición técnica de paso que ofrece finalmente es: «El paso es un tipo de narratio encuadrable en el género retórico epidíctico, siendo el motivo evangélico su tema ('propositio')».

${ }^{158}$ Cf. H. Lausberg, Manual de retórica literaria (Madrid, 1967), 235. De este autor toma A. Pego algunos elementos retóricos que trata de individuar en los pasos, como la expolitio, que consiste en pulir y redondear el pensamiento (res) mediante la variación (variatio) de su forma elocutiva (verba) y de los pensamientos secundarios pertenecientes a la idea principal», la evidentia, la braquiloquía...

${ }^{159} \mathrm{Cita}$ al respecto la frase de Fray Luis de Granada: «Y no pienses esto como cosa ya pasada, sino como presente; no como dolor ajeno, sino como tuyo propio» (Libro de la oración y meditación, f. $63 r)$.

${ }^{160} \mathrm{Cf}$. M. Fumaroli, L'âge de l'éloquence. Rhétorique et «res literaria» de la Renaissance au seuil de l'époque classique (París, 1994); G. Giuseppina, La parola e l'immagine. Strategie della persuasione religiosa nella Spagna secentesca (Pisa, 2003). Dice que Erasmo, como buen «ciceroniano», se pregunta cómo utilizar la elocuencia pagana para predicar el mensaje cristiano. 


\section{Jesús Pulido Arriero}

Otros autores han comparado este género literario con la descriptio ${ }^{161}$ o la écfrasis o hipotiposis (descripción animada). Se trata de géneros abiertos, que usan todo tipo de recursos para aportar realismo e introducir a los lectores en la realidad que describen ${ }^{162}$.

El predicador o el escritor del recogimiento español, mediante el uso de todo tipo de recursos literarios, es capaz de transformar la realidad y convertir el rostro de Cristo desfigurado en la pasión en expresión de la mayor belleza. La edad moderna descubrió la capacidad del ingenio humano para crear belleza ideal, más allá de la realidad que encuentra a su alrededor ${ }^{163}$.

\section{Bibliografía}

Andrés Martín, Melquiades. Historia de la mística en la Edad de Oro en España y América. Madrid: Biblioteca de Autores Cristianos, 1994.

Andrés Martín, Melquiades. La Teología española en el siglo XVI (2 vols.). Madrid: Biblioteca de Autores Cristianos, 1976-1977.

Andrés Martín, Melquiades. «En torno a la 'theologia crucis' en la espiritualidad española (1450-1559)». Diálogo ecuménico 6 (1971): 359-390.

Baier, Karl. Meditation und Moderne. Zur Genese eines Kernbereichs moderner Spiritualität in der Wechselwirkung zwischen Westeuropa, Nordamerika und Asien, I. Würzburg: Königshausen u. Neumann, 2009.

Barbero, Amilcare. "Complessi devozionali europei dal quattrocento al settecento", en Saggio storico sulla devozione alla Via Crucis, coord. por Barbero, Amilcare et al., Ponzano Monterrato: Atlas, 2004, 43-61

Bestul, Thomas. H. Texts of the Passion: Latin Devotional Literature and Medieval Society. Philadelphia: University of Pennsylvania Press, 1996.

Boon, Jessica A. The Mystical Language of Recollection: Bernardino de Laredo and the 'Subida al Monte Sion'. Tesis doctoral. Universidad de Pensilvania, 2004.

Köpf, Ulrich. «Passionsfrömmigkeit», en Theologische Realenzyklopadie XXVII. Berlin, 1997, 722-764.

Martínez Cuesta, Ángel. «El movimiento recoleto en los siglos XVI y XVII». Recollectio 5 (1982): 5-47

Pego Puigbó, Armando. «Un ejemplo de constitución genérica en la literatura espiritual: el 'paso' del Ecce Homo». Revista de Literatura 126 (2001): 369-400.

\footnotetext{
${ }^{161}$ Cf. G. Ledda, «Predicar a los ojos», Edad de Oro vol. VIII (1989): 129-143.

${ }^{162} \mathrm{Cf}$. M. Fumaroli, L'âge de l'éloquence.

${ }^{163}$ R. O. Jones, Historia de la literatura española II. Siglo de oro: poesía y prosa (Barcelona, 1983), $55 \mathrm{ss}$.
} 


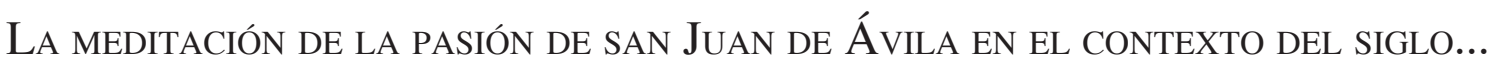

Pulido Arriero, Jesús. La meditación de la Pasión en San Juan de Ávila. Aportación a la Teología Espiritual. Tesis doctoral. Facoltà di Teologia Teresianum, Roma, 2015.

Requena Moita, Juan Carlos. La espiritualidad española de los siglos XVXVII a través de las Vita Christi. Tesis doctoral. Universidad de Barcelona, 1997.

Ricard, Robert. «El tema de Jesús crucificado en la obra de algunos escritores españoles de los siglos XVI y XVII», en id., Estudios de literatura religiosa española. Madrid: Editorial Credos, 1964, 227-245.

Vanderbroucke, François. «La dévotion au Crucifié à la fin du Moyen Age». La Maison-Dieu 75 (1963): 34-149.

Villalobos Hennesy, Marlene. «Passion Devotion, Penitencial Reading, and the Manuscript Page: 'The Hours of the Cross' in London, British Library Additional 37049». Medieval Studies 66 (2004): 213-252. 